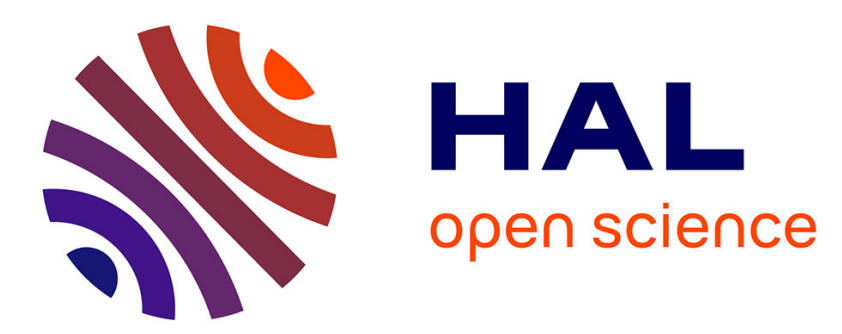

\title{
Titan's ionospheric composition and structure: Photochemical modeling of Cassini INMS data
}

J. H. Westlake, J. H. Waite Jr., K. E. Mandt, Nathalie Carrasco, J. M. Bell, B. A. Magee, J.-E. Wahlund

\section{- To cite this version:}

J. H. Westlake, J. H. Waite Jr., K. E. Mandt, Nathalie Carrasco, J. M. Bell, et al.. Titan's ionospheric composition and structure: Photochemical modeling of Cassini INMS data. Journal of Geophysical Research. Planets, 2012, 117, pp.E01003. 10.1029/2011JE003883 . hal-00659857

\section{HAL Id: hal-00659857 https://hal.science/hal-00659857}

Submitted on 16 Aug 2020

HAL is a multi-disciplinary open access archive for the deposit and dissemination of scientific research documents, whether they are published or not. The documents may come from teaching and research institutions in France or abroad, or from public or private research centers.
L'archive ouverte pluridisciplinaire HAL, est destinée au dépôt et à la diffusion de documents scientifiques de niveau recherche, publiés ou non, émanant des établissements d'enseignement et de recherche français ou étrangers, des laboratoires publics ou privés. 


\title{
Titan's ionospheric composition and structure: Photochemical modeling of Cassini INMS data
}

\author{
J. H. Westlake, ${ }^{1}$ J. H. Waite Jr., ${ }^{1,2}$ K. E. Mandt,,${ }^{2,3}$ N. Carrasco, ${ }^{4}$ J. M. Bell, ${ }^{2}$ B. A. Magee, ${ }^{2}$ \\ and J.-E. Wahlund ${ }^{5}$ \\ Received 9 June 2011; revised 6 October 2011; accepted 1 November 2011; published 12 January 2012.
}

[1] Titan's upper atmosphere produces an ionosphere at high altitudes from photoionization and electron impact that exhibits complex chemical processes in which hydrocarbons and nitrogen-containing molecules are produced through ion-molecule reactions. The structure and composition of Titan's ionosphere has been extensively investigated by the Ion and Neutral Mass Spectrometer (INMS) onboard the Cassini spacecraft. We present a detailed study using linear correlation analysis, 1-D photochemical modeling, and empirical modeling of Titan's dayside ionosphere constrained by Cassini measurements. The 1-D photochemical model is found to reproduce the primary photoionization products of $\mathrm{N}_{2}$ and $\mathrm{CH}_{4}$. The major ions, $\mathrm{CH}_{5}^{+}, \mathrm{C}_{2} \mathrm{H}_{5}^{+}$, and $\mathrm{HCNH}^{+}$are studied extensively to determine the primary processes controlling their production and loss. To further investigate the chemistry of Titan's ionosphere we present an empirical model of the ion densities that calculates the ion densities using the production and loss rates derived from the INMS data. We find that the chemistry included in our model sufficiently reproduces the hydrocarbon species as observed by the INMS. However, we find that the chemistry from previous models appears insufficient to accurately reproduce the nitrogen-containing organic compound abundances observed by the INMS. The major ion, $\mathrm{HCNH}^{+}$, is found to be overproduced in both the empirical and 1-D photochemical models. We analyze the processes producing and consuming $\mathrm{HCNH}^{+}$in order to determine the cause of this discrepancy. We find that a significant chemical loss process is needed. We suggest that the loss process must be with one of the major components, namely $\mathrm{C}_{2} \mathrm{H}_{2}, \mathrm{C}_{2} \mathrm{H}_{4}$, or $\mathrm{H}_{2}$.

Citation: Westlake, J. H., J. H. Waite Jr., K. E. Mandt, N. Carrasco, J. M. Bell, B. A. Magee, and J.-E. Wahlund (2012), Titan's ionospheric composition and structure: Photochemical modeling of Cassini INMS data, J. Geophys. Res., 117, E01003, doi:10.1029/2011JE003883.

\section{Introduction}

[2] Titan's atmosphere harbors a high altitude ionosphere in which the energy given to the major neutral molecules $\mathrm{N}_{2}$ and $\mathrm{CH}_{4}$ through absorption of the Sun's actinic spectrum and through the interaction of Saturn's magnetosphere with Titan's upper atmosphere is used to chemically convert these species into complex molecules. Solar photons act to ionize and dissociate $\mathrm{N}_{2}$ and $\mathrm{CH}_{4}$ providing energy that has been shown to be the primary driver of Titan's ionosphere. Dayside ion densities are roughly a factor of 5 greater than those

\footnotetext{
${ }^{1}$ Applied Physics Laboratory, Johns Hopkins University, Laurel, Maryland, USA.

${ }^{2}$ Space Science and Engineering Division, Southwest Research Institute, San Antonio, Texas, USA.

${ }^{3}$ Department of Environmental and Civil Engineering, University of Texas at San Antonio, San Antonio, Texas, USA.

${ }^{4}$ Laboratoire Atmosphres, Milieux, Observations Spatiales, Universit de Versailles Saint-Quentin-en-Yvelines, Guyancourt, France.

${ }^{5}$ Swedish Institute of Space Physics, Uppsala, Sweden.

Copyright 2012 by the American Geophysical Union. 0148-0227/12/2011JE003883
}

on the nightside [Agren et al., 2009]. Titan's nightside ionosphere is expected to be driven by magnetospheric particle precipitation, in which electrons likely play a major role [Cravens et al., 2009]. The energy provided in either case is generally sufficient to both dissociate and ionize $\mathrm{N}_{2}$ and $\mathrm{CH}_{4}$.

[3] The chain of reactions that follows the photodissociation and photoionization of $\mathrm{N}_{2}$ and $\mathrm{CH}_{4}$ has been studied both in the laboratory and through photochemical modeling. Reviews of the chemistry relevant to Titan's ionosphere have identified chemical pathways through ionmolecule reactions producing ions larger than benzene $\left(\mathrm{C}_{6} \mathrm{H}_{6}\right)[M c E w a n$ and Anicich, 2007; Anicich and McEwan, 1997]. Modeling approaches have shown that the ionmolecule chemistry at Titan is significantly faster than comparable neutral-neutral chemistry at the ionospheric altitudes implying that the ionosphere is intimately involved in producing the larger molecules observed by Cassini [Vuitton et al., 2006; Waite et al., 2007].

[4] Several authors have produced photochemical models of Titan's atmosphere that include ion chemistry. Fox and 
Yelle [1997] produced a 1-D photochemical model using a complex hydrocarbon chemistry reaction set and showing that in Titan's reducing atmosphere that proton exchange reactions are important. Keller et al. [1992, 1998] produced a 1-D photochemical model of Titan's high altitude ionosphere using as input the neutral atmosphere of Yung et al. [1984] and a combination of solar ionization and magnetospheric electron precipitation. It showed that the hydrocarbon chemistry of Titan's upper atmosphere produces several hydrocarbon ion species with significant densities. This model also reproduced the general structure of the ionosphere with peak densities near $1150 \mathrm{~km}$ dominated by $\mathrm{HCNH}^{+}$, $\mathrm{C}_{2} \mathrm{H}_{5}^{+}$, and $\mathrm{CH}_{5}^{+}$. Robertson et al. [2009] and Cravens et al. [2009] advanced the model of Keller et al. [1998] to analyze Titan's ionosphere and study the data returned from the Cassini INMS. Robertson et al. [2009] also included a study of the sensitivity of photochemical models to the minor neutral abundances used. Banaszkiewicz et al. [2000], Wilson and Atreya [2004], De La Haye et al. [2008], and Krasnopolsky [2009] have all produced coupled models of Titan's neutral atmosphere and ionosphere. For a more complete review of the plethora of models which have been produced for Titan's ionosphere the reader is referred to the reviews by Cravens et al. [2010] and Vuitton et al. [2009b].

[5] In light of the complex ion spectra obtained by the Cassini INMS, Vuitton et al. [2006, 2007] produced a 0D model of Titan's ionosphere. In this model a snapshot of the atmosphere at one altitude was obtained and spectra were produced through balancing the localized production and loss of ions. This work identified several nitrogen-containing species as significant contributors to the observed spectrum. Vuitton et al. [2008] expanded this model to study the production of benzene in Titan's ionosphere by calculating the ion densities at several altitudes to produce a 1-D photochemical model similar to that of Keller et al. [1992]. Their results were then compared to the INMS data from the T17 flyby yielding in some cases suitable correspondence, but in the hydrocarbons heavier than $\mathrm{C}_{4} \mathrm{H}_{2}^{+}$good correspondence was only found above $1100 \mathrm{~km}$.

[6] In addition several authors have investigated the sources and sinks of ionization in Titan's ionosphere. Cravens et al. [2005] calculated electron densities using a two-stream electron transport model coupled to a photochemical ionospheric model. Robertson et al. [2009] also analyzed Titan's ionospheric structure finding that the dayside ionosphere above about $1100 \mathrm{~km}$ was well represented by photochemical modeling utilizing Cassini data to constrain the model. Galand et al. [2010] utilized several data sets from the Cassini spacecraft to determine the effective recombination coefficient. This recombination coefficient was found to increase with decreasing altitude due to the changing ionospheric composition. Lavvas et al. [2011] analyzed the primary photochemical products in the ionosphere yielding production rate profiles of several radical and ionized species. Richard et al. [2011] analyzed the electron and ion temperatures at Titan finding that, on Titan's dayside, solar inputs can reasonably explain ionospheric electron temperatures at altitudes between about $1400 \mathrm{~km}$ and $1000 \mathrm{~km}$.

[7] In this work we use the ion densities obtained by the INMS to guide the modeling process. We first look for correlations within the INMS ion data set in an attempt to reveal growth pathways that may not have been studied in the laboratory. We produce a 1-D photochemical model to study the composition and structure of the ionosphere. We then produce an empirical model based on the INMS data to study the production and loss of individual ions. The results are compared to the INMS ion data and the successes and failures of the current modeling approach are discussed.

\section{Cassini INMS Data}

[8] Fundamentally, ions incident on the open source of the Cassini INMS are measured by first focusing the incident beam, then turning it along a 90 degree bend using a quadrupole switching lens. The ion beam is again focused into the mass analyzer, separated according to the mass per charge $(\mathrm{m} / \mathrm{z})$ in the main quadrupole, and finally detected using a channel electron multiplier. The transmission of ions through the instrument is measured in flight by varying the voltages on the switching lenses and determining how the count rate varies; this is referred to as an energy scan in INMS parlance. This measurement generally occurs at altitudes below $1000 \mathrm{~km}$ and is performed for several mass bins. It is from this measurement that we have determined the response of INMS to the energy of the incoming ion beam. In order to correct for any transmission loss due to a difference in the predicted and actual energy of the ion beam, we must correct for spacecraft potential and ion wind/ drift velocities. Careful analysis of the in flight calibration (K. Mandt et al., Ion densities and composition of Titan's upper atmosphere derived from the Cassini ion neutral mass spectrometer: Analysis methods and model comparison, manuscript in preparation, 2012) and collaboration with other Cassini instrument teams allows us to have a high level of confidence in the ion densities obtained by the INMS using the present set of analysis software.

[9] Several authors have displayed INMS ion densities in the literature using various calibrations and densities [see Cravens et al., 2010]. We utilize the calibration study of Mandt et al. (manuscript in preparation, 2012) to determine the ion densities measured by the INMS. This study utilizes a cross-calibration of the obtained INMS densities with the CAPS-IBS and Langmuir Probe electron densities. It should be noted that the change in the newer calibrated INMS ion densities only show a difference of about $25 \%$ versus the majority of the previous works (Mandt et al., manuscript in preparation, 2012). The densities reported here are consistent among all three of these instruments. Furthermore, the study of J. H. Waite et al. (In-flight and ground calibration of the Cassini ion neutral mass spectrometer: Determination of the calibration constant required for calculation of ion and ambient neutral densities and related uncertainties, manuscript in preparation, 2012) found that the INMS neutral measurements should be corrected by a factor of 3.0 which we adopt here.

[10] In this work we use data from fourteen Titan flybys between T5 and T59, but focus on the T40 flyby that occurred on January 5, 2008. This flyby has a closest approach altitude of $1010 \mathrm{~km}$ that occurred at latitude of 11.7 S, west longitude of 130.4 , local solar time of 13.0 hours and a solar zenith angle of 37.6 degrees. This flyby takes place completely on the dayside of Titan and is therefore expected to have a majority of its ions produced through solar photoionization. The neutral atmosphere during this flyby 


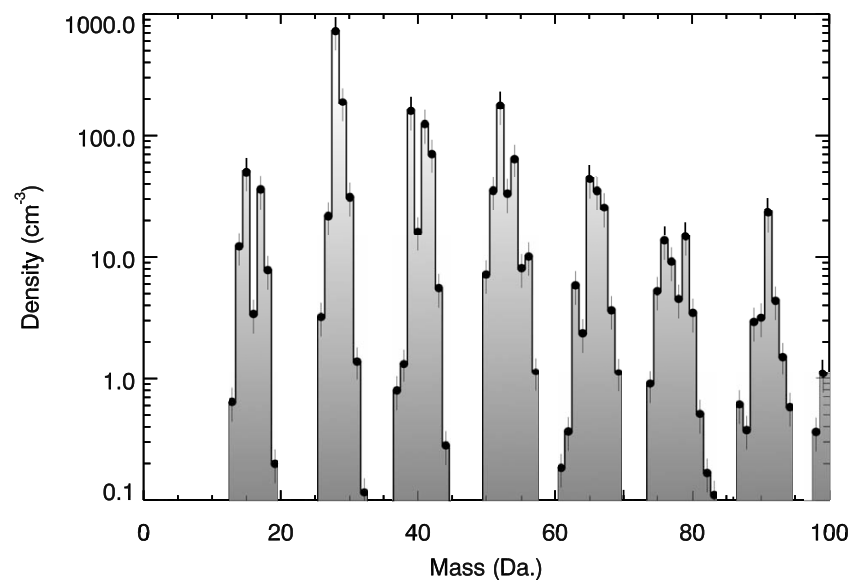

Figure 1. The mass spectrum obtained using the open source ion mode of the Cassini INMS during the inbound leg of the T40 flyby at $1079 \mathrm{~km}$ altitude. The spectrum is shown as a histogram with bins of $1 \mathrm{Da}$. resolution. The thin vertical lines in the middle of each bin correspond to the statistical uncertainty in the measurement.

has an average thermospheric temperature of $141 \mathrm{~K}$ as measured by the nitrogen scale height [Westlake et al., 2011]. The T40 flyby is chosen because it is a dayside flyby in which high quality INMS ion data was retrieved. The flyby was classified by Rymer et al. [2009] to be bi-modal and found to have a neutral temperature of $141 \mathrm{~K}$ [Westlake et al., 2011]. Shown in Figure 1 is an example of a mass spectrum obtained by the Cassini INMS during the inbound leg of the T40 flyby at $1079 \mathrm{~km}$ altitude. Notice in this spectrum that there are seven distinct mass groupings that are separated by roughly 12-14 Da. The mass groupings will be referred to throughout this paper as group 1,2,3, etc. indicating that the ions within that group contain 1, 2, 3, or more carbon or nitrogen atoms.

[11] In this study we also utilize neutral data from the INMS closed source measurements. The methodology of Magee et al. [2009] is used to reduce the neutral data yielding high time resolution measurements of $\mathrm{N}_{2}, \mathrm{CH}_{4}$, and $\mathrm{H}_{2}$. The deconvolution process restricts the usage of the direct measurements of the minor neutral densities to globally averaged values at selected altitudes. These values have been produced through the study of Magee et al. [2009] yielding minor species densities at altitudes near $1050 \mathrm{~km}$. Table 1 shows a comparison of the minor neutral species mixing ratios obtained through the Magee et al. [2009] method compared to those obtained through the method of Cui et al. [2009]. For $\mathrm{C}_{2} \mathrm{H}_{2}$ and $\mathrm{C}_{2} \mathrm{H}_{4}$ the values are significantly different because the study of Cui et al. [2009] assumes a fixed ratio between the two molecules while the study of Magee et al. [2009] produces independent fits for each species. We choose the Magee et al. [2009] method over the Cui et al. [2009] method because it provides HCN densities and independent $\mathrm{C}_{2} \mathrm{H}_{2}$ and $\mathrm{C}_{2} \mathrm{H}_{4}$ densities.

\section{Study of Correlations Within the INMS Data}

[12] The goal of this study is to probe the primary chemical processes of the ions observed by the Cassini INMS. The rate at which an ion-molecule reaction takes place is quantified by a rate constant that can be used in conjunction with the reacting ion and neutral density to determine the production or loss rate of the ion in question. If the observed ion density is primarily controlled by a specific production process, this connection between the reactant ion and the product ion will be apparent. We can express this connection through an analysis of the correlations between the densities observed by the various mass bins in the Cassini INMS data.

[13] We utilize the Pearson product-moment correlation coefficient to measure the linear dependence between the densities observed in two mass bins. Pearson's productmoment correlation coefficient is defined as

$$
r=\frac{\sum_{i}\left(M 1_{i}-\bar{M} 1\right)\left(M 2_{i}-\bar{M} 2\right)}{\sqrt{\sqrt{\sum_{i}\left(M 1_{i}-\bar{M} 1\right)^{2}} \sqrt{\sum_{i}\left(M 2_{i}-\bar{M} 2\right)^{2}}}}
$$

where $M 1$ and $M 2$ are the densities recorded for mass 1 and 2 in the comparison. There exist other methods to determine the correlation including the model independent rank correlations such as the Kendall-tau or Spearman rank correlation coefficients. We find that there is little difference in the derived correlations when using these various methods and therefore stay with the simple Pearson correlation. In this framework the correlation coefficient is given by the covariance of the two mass bins divided by their standard deviations.

[14] We collect data from the fourteen Titan flybys and calculate the Pearson correlation coefficient between two different mass bins within the same spectrum. We calculate a single correlation coefficient that covers all measurements within the chosen altitude range from all of the chosen flybys. We isolate the region over which the correlation coefficient is calculated to be above the photoionization peak. This allows for the determination of mass bins that are most likely to contain ions produced through reactions with the major ions $\mathrm{CH}_{5}^{+}, \mathrm{C}_{2} \mathrm{H}_{5}^{+}$, and $\mathrm{HCNH}^{+}$. The photoionization peak occurs roughly below $1150 \mathrm{~km}$ in general. We therefore use only the INMS ion data above $1200 \mathrm{~km}$ and below $2000 \mathrm{~km}$ to be sure that the ionization peak is not included and calculate the correlation coefficients.

[15] Figure 2 shows the calculated correlation coefficients for all of the mass bins 12-99 in the INMS data taken over the entirety of the fourteen flybys studied. Each pixel in the

Table 1. Neutral Mixing Ratios Obtained by Various Methods From the INMS Closed Source

\begin{tabular}{lccc}
\hline Species & $\begin{array}{c}\text { Magee et al. }[2009] \\
(1050 \mathrm{~km})\end{array}$ & $\begin{array}{c}\text { Cui et al. [2009] } \\
(1025 \mathrm{~km})\end{array}$ & $\begin{array}{c}\text { Difference } \\
(\%)\end{array}$ \\
\hline $\mathrm{C}_{2} \mathrm{H}_{2}$ & $(3.42 \pm 0.14) \times 10^{-4}$ & $(1.68 \pm 0.01) \times 10^{-4}$ & 51 \\
$\mathrm{C}_{2} \mathrm{H}_{4}$ & $(3.91 \pm 0.16) \times 10^{-4}$ & $(5.04 \pm 0.04) \times 10^{-4}$ & 29 \\
$\mathrm{C}_{2} \mathrm{H}_{6}$ & $(4.57 \pm 0.74) \times 10^{-5}$ & $(4.05 \pm 0.19) \times 10^{-5}$ & 11 \\
$\mathrm{HCN}$ & $(2.44 \pm 0.10) \times 10^{-4}$ & & \\
$\mathrm{C}_{3} \mathrm{H}_{4}$ & $(9.20 \pm 0.46) \times 10^{-6}$ & $(9.02 \pm 0.22) \times 10^{-6}$ & 2 \\
$\mathrm{C}_{3} \mathrm{H}_{6}$ & $(2.33 \pm 0.18) \times 10^{-6}$ & & \\
$\mathrm{C}_{3} \mathrm{H}_{8}$ & $(2.87 \pm 0.26) \times 10^{-6}$ & $<1.84 \times 10^{-6}$ & 36 \\
$\mathrm{C}_{4} \mathrm{H}_{2}$ & $(5.55 \pm 0.25) \times 10^{-6}$ & $(4.92 \pm 0.10) \times 10^{-6}$ & 11 \\
$\mathrm{C}_{2} \mathrm{~N}_{2}$ & $(2.14 \pm 0.12) \times 10^{-6}$ & $(1.70 \pm 0.07) \times 10^{-6}$ & 21 \\
$\mathrm{HC}_{3} \mathrm{~N}$ & $(1.48 \pm 0.09) \times 10^{-6}$ & $(1.43 \pm 0.06) \times 10^{-6}$ & 3 \\
$\mathrm{C}_{2} \mathrm{H}_{3} \mathrm{CN}$ & $(3.46 \pm 0.51) \times 10^{-7}$ & $<4.00 \times 10^{-7}$ & 16 \\
$\mathrm{C}_{2} \mathrm{H}_{5} \mathrm{CN}$ & $(1.54 \pm 0.48) \times 10^{-7}$ & & \\
$\mathrm{C}_{6} \mathrm{H}_{6}$ & $(2.48 \pm 0.11) \times 10^{-6}$ & $(2.42 \pm 0.05) \times 10^{-6}$ & 2 \\
\hline
\end{tabular}




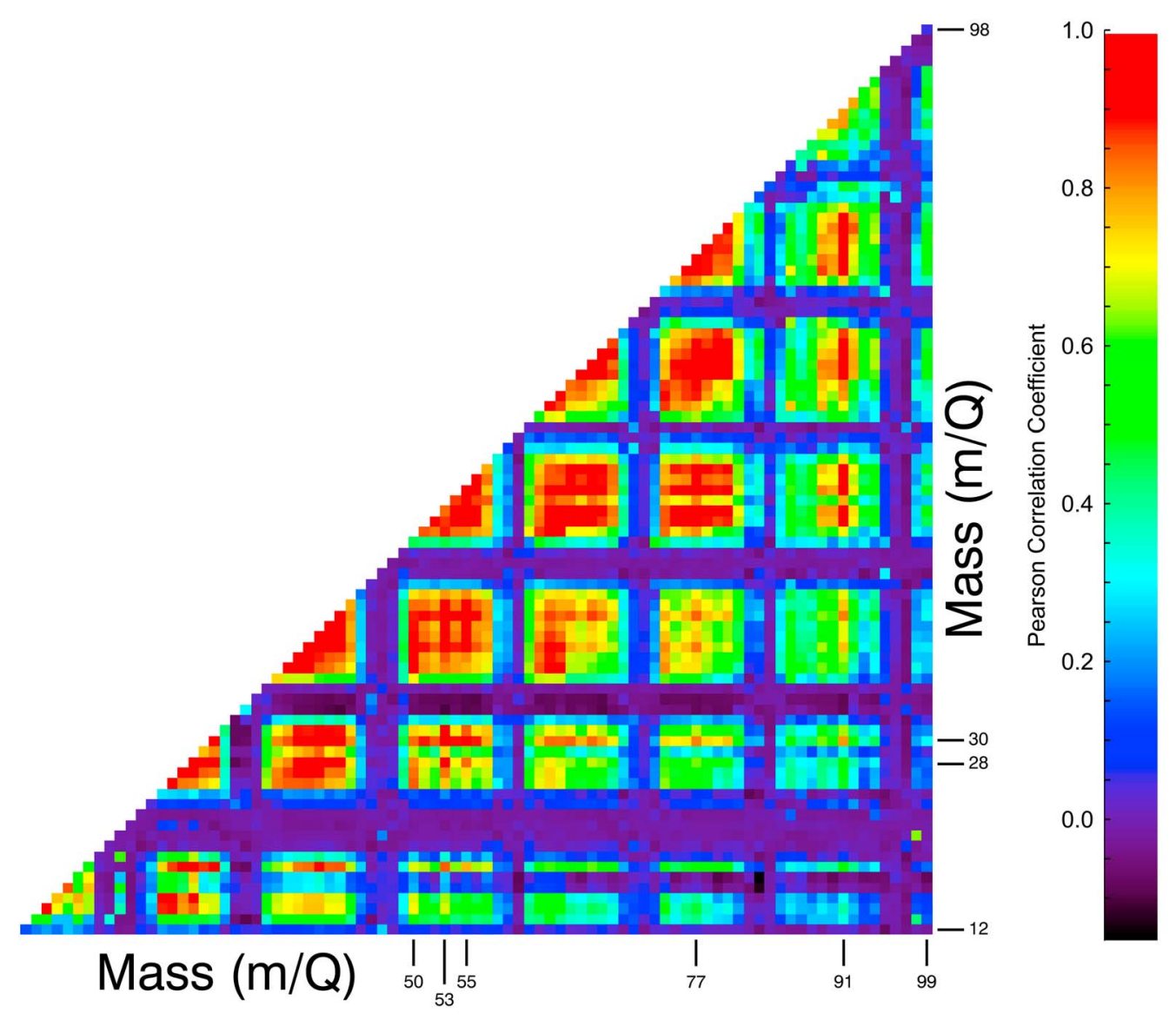

Figure 2. This map shows the mass bin to mass bin Pearson $r$ correlation coefficient for the INMS ions as recorded through the T5-T59 flybys.

figure represents a correlation coefficient between different masses. The main diagonal establishes the one-to-one correlation of a mass bin to itself. The triangles that come off of the main diagonal represent each mass grouping in the INMS spectrum. These correlations are high for most of the groups. The clusters that roughly make up squares observed to the right of the triangles represent the correlation between adjacent mass groups. In general these correlations represent the addition of one carbon or nitrogen. Further square groupings to the right represent correlations to mass groupings which are two, three, or more mass groups away representing the addition of more than one carbon or nitrogen.

[16] Several patterns emerge from this correlation study. The clearest macro scale structure is the clustering of groups of high correlation corresponding to the hydrocarbon chemistry of Titan's ionosphere. Some of the most efficient ionmolecule reactions for the pure hydrocarbons are those with methane, acetylene, and ethylene, therefore each carbon group appears to be highly correlated with its adjacent group as well as those that are two groups away. This emphasizes the importance of chemical pathways that utilize small hydrocarbon building blocks such as methane, acetylene, and ethylene. These processes are favored due to the high abundance of these building blocks. Given the multitude of processes that are suggested to contribute to the production and loss of these ions it is difficult to isolate individual parameters through these comparisons.
[17] Missing in the correlations are the jumps of more than two carbon groups that would be indicative of large neutrals being the primary source of growth to large ions. If neutral species such as $\mathrm{C}_{6} \mathrm{H}_{6}$ or $\mathrm{C}_{4} \mathrm{H}_{2}$ are responsible for the production of the large ions then one would expect to see higher correlation between specific masses that are separated by 78 or $50 \mathrm{amu}$ (the mass of benzene and diacetylene). This is important, as the mechanism proposed for producing several larger ions is the proton exchange of $\mathrm{CH}_{5}^{+}, \mathrm{C}_{2} \mathrm{H}_{5}^{+}$, and $\mathrm{HCNH}^{+}$with larger neutral molecules. The correlations within the INMS data seem to indicate that these ions may be built from small ion and neutral building blocks instead of being solely produced through small ions proton transferring to large neutrals.

[18] We note that correlation does not imply causality and that it is possible to have correlations between ions that are produced at similar altitudes. However, the relations that have the greatest correlation (generally correlation coefficients greater than 0.8 or in the red in Figure 2) appear to be linked through chemical reactions. The lower values of the correlation coefficient may imply some link through the chemistry, but these are generally not the most important reactions.

\section{One-Dimensional Photochemical Model}

[19] The 1-D photochemical model builds on several previous models [Keller et al., 1992, 1998; Vuitton et al., 2007; 


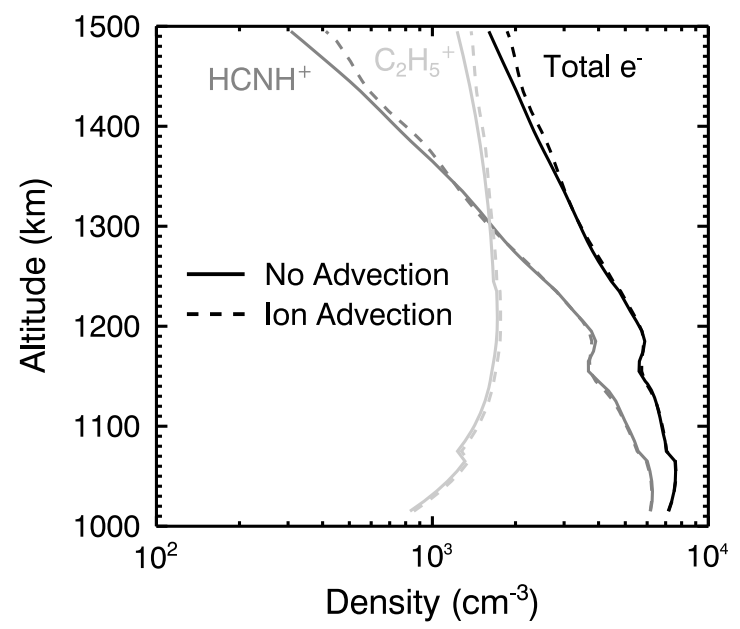

Figure 3. Shown are two model runs using the T-GITM model of Bell et al. [2010a]. The solid profile gives the model results without ion advection while the dashed profile includes ion advection. The black profile shows the total electron content in the model, the dark grey shows the $\mathrm{HCNH}^{+}$density and the light grey gives the $\mathrm{C}_{2} \mathrm{H}_{5}^{+}$density.

Carrasco et al., 2008b; De La Haye et al., 2008; Cravens et al., 2005; Robertson et al., 2009]. This model solves the continuity equation for each ion species using Newton's method for each altitude independently. The continuity equation is given by

$$
\frac{d n_{i}}{d t}=P_{i}-L_{i} n_{i}
$$

where $n_{i}$ is the density of the ion species, $P_{i}$ and $L_{i}$ are the production and loss rates of the ion species $i$. In this model ion production is primarily due to photoionization and ionneutral reactions while ion loss is due to ion-neutral reactions and electron recombination. We have neglected the transport term of the more generalized continuity equation as Cravens et al. [2009] showed that below $1400 \mathrm{~km}$ chemical time constants were significantly greater than transport time constants. Furthermore, comparisons between the Kansas photochemical model and the MHD model of Ma et al. [2006] showed that in neglecting the transport terms the photochemical model matched the MHD model for altitudes below about $1400 \mathrm{~km}$. We also note that the MHD calculations produced lesser densities at the higher altitudes, indicating that the transport terms in the MHD model are removing ions from the system.

[20] We have considered ion advection using the Titan Global Ionosphere Thermosphere Model (T-GITM) of Bell et al. [2010a]. We emphasize that we are not attempting to reproduce the exact ionospheric densities, but instead we are merely using T-GITM to test whether or not ion advection will significantly influence the calculated ion densities in the 1-D photochemical model. In order to accomplish this, we employ the three-dimensional (3-D) T-GITM framework, which calculates the coupled energetics, dynamics, and composition of Titan's upper atmosphere. Bell et al. [2010a, 2010b, 2011] validated the 1-D model by self-consistently reproducing the average INMS major neutral densities and mixing ratios between TA and T40. T-GITM itself is a nonhydrostatic 3-D Navier-Stokes Global model for the Ionosphere-Thermosphere region of Titan's atmosphere, based upon the Earth Global Ionosphere-Thermosphere Model (GITM) of Ridley et al. [2006]. To investigate the case of maximum vertical transport, we omitted the draped magnetic fields expected in Titan's ionosphere, which would reduce the total vertical transport by deflecting the ions horizontally due to Lorentzian forces. Shown in Figure 3 are the results of this study. We find that, in allowing the ions to vertically advect with the neutral gas in T-GITM, that this process had little or no effect on the derived densities over a purely photochemical ionosphere that is represented by the no advection case.

[21] The photon flux is simulated using the EUVAC model [Richards et al., 1994] in which the method of Tobiska and Barth [1990] is used with additional bins for lower wavelength photons using the same method as Robertson et al. [2009]. For the T40 flyby we use a F10.7 value of 77.1 and the $\mathrm{F}_{a v} 10.7$ value of 69.4 in the EUVAC calculation (the values were obtained from the National Geophysical Data Center at www.ngdc.noaa.gov). We use the cross sections compiled by De La Haye et al. [2008]. The production rate due to photoionization is described by

$$
P_{\text {photo }}=\sum_{k} Q_{Y i}(\lambda) \sigma_{k}^{a}(\lambda) \Phi(z, \lambda)\left[n_{k}\right],
$$

where $\Phi(z, \lambda)$ is the photon flux calculated using the F10.7 solar radio flux values and attenuated by the atmosphere above the measurement point, $\sigma_{k}^{a}(\lambda)$ is the photoabsorption cross section for the neutral species at wavelength $\lambda$, and $Q_{Y i}(\lambda)$ is the quantum yield. Photoionization is included for the species $\mathrm{H}, \mathrm{H}_{2}, \mathrm{CH}_{4}, \mathrm{C}_{2} \mathrm{H}_{2}, \mathrm{C}_{2} \mathrm{H}_{4}, \mathrm{C}_{2} \mathrm{H}_{6}, \mathrm{C}_{4} \mathrm{H}_{2}, \mathrm{~N}, \mathrm{~N}_{2}$, $\mathrm{HCN}$, and $\mathrm{C}_{6} \mathrm{H}_{6}$. We utilize the same cross sections and quantum yields as were used by De La Haye et al. [2008]. The optical depth of the atmosphere is calculated for each point using the INMS neutral data in which $\mathrm{N}_{2}$, and $\mathrm{CH}_{4}$ are considered the main absorbers. We find that the T40 flyby the majority of the ionization results from photoionization and that no additional magnetospheric electron inputs are required to reproduce the altitude profiles. We include some amount of electron precipitation at the highest altitudes. The altitude profile of magnetospheric electrons available was calculated by a two-stream electron precipitation model for the conditions of the TA flyby as calculated by De La Haye et al. [2008] and scaled to obtain the best fit for the primary ionization products.

[22] The neutral atmosphere shown in Figure 4 is produced using the INMS T40 neutral data for $\mathrm{N}_{2}, \mathrm{CH}_{4}$, and $\mathrm{H}_{2}$. The mixing ratios of the minor molecules $\mathrm{C}_{2} \mathrm{H}_{2}, \mathrm{C}_{2} \mathrm{H}_{4}$, $\mathrm{C}_{2} \mathrm{H}_{6}, \mathrm{HCN}, \mathrm{CH}_{3} \mathrm{C}_{2} \mathrm{H}, \mathrm{C}_{3} \mathrm{H}_{6}, \mathrm{C}_{3} \mathrm{H}_{8}, \mathrm{C}_{4} \mathrm{H}_{2}, \mathrm{C}_{2} \mathrm{~N}_{2}, \mathrm{HC}_{3} \mathrm{~N}$, $\mathrm{C}_{2} \mathrm{H}_{3} \mathrm{CN}, \mathrm{C}_{2} \mathrm{H}_{5} \mathrm{CN}$, and $\mathrm{C}_{6} \mathrm{H}_{6}$ are constrained at an altitude of $1050 \mathrm{~km}$ from the global composition analysis of Magee et al. [2009]. For the minor species $\mathrm{H}, \mathrm{N}\left({ }^{4} \mathrm{~S}\right), \mathrm{CH},{ }^{1} \mathrm{CH}_{2}$, ${ }^{3} \mathrm{CH}_{2}, \mathrm{CH}_{3}$, and $\mathrm{HCNH}$ we use the density profiles from De La Haye et al. [2008]. Shown in Figure 4 are the densities of the main species of the neutral background atmosphere.

[23] The work of Cui et al. [2009] also gives averaged minor neutral mixing ratios from the INMS using a different method. For a detailed discussion of the two methods and the differences in the results the reader is referred to Magee 


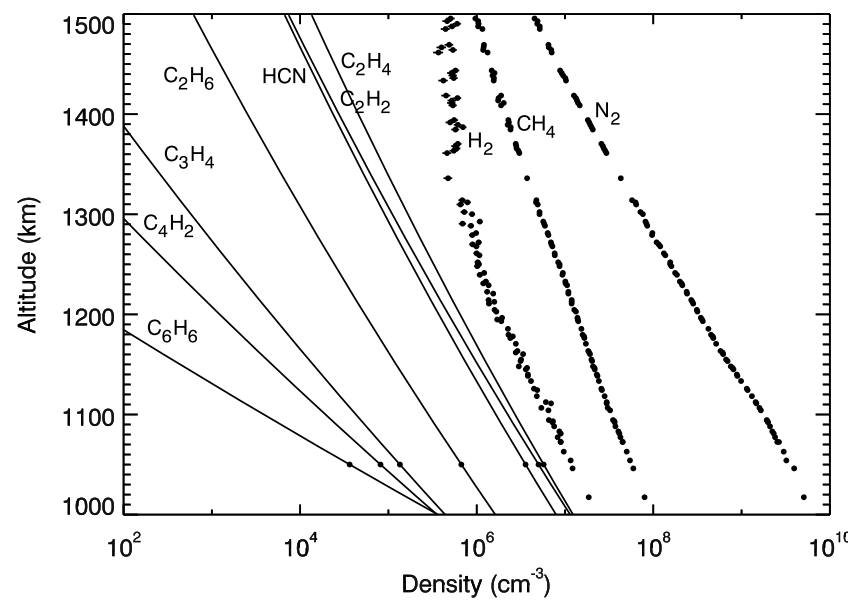

Figure 4. Shown are the densities of the neutrals used to calculate the altitude profiles of the ions. The points correspond to the INMS observations taken during the T40 flyby on the ingress portion of the flyby. The statistical error of these points is roughly equal to the width of the points. The density profiles of the minor neutrals correspond to the scale height of each species considering that their mixing ratio is fixed at $1050 \mathrm{~km}$ using the values of Magee et al. [2009] and an atmospheric temperature of $141 \mathrm{~K}$.

et al. [2009]. Here we note that the study of Cui et al. [2009] gives averaged altitude profiles from about $980 \mathrm{~km}$ to $1150 \mathrm{~km}$ for $\mathrm{C}_{2} \mathrm{H}_{2} / \mathrm{C}_{2} \mathrm{H}_{4}$ (Cui et al. [2009] treated these as a combined species), $\mathrm{C}_{4} \mathrm{H}_{2}, \mathrm{C}_{2} \mathrm{~N}_{2}, \mathrm{HC}_{3} \mathrm{~N}, \mathrm{C}_{2} \mathrm{H}_{3} \mathrm{CN}$, and $\mathrm{C}_{6} \mathrm{H}_{6}$. We do not use these altitude profiles directly as these compounds are expected to be under the control of diffusive processes in this region and will hence follow their diffusive scale height. The scale height is dependent on the temperature that has been shown to be highly variable from pass to pass [Westlake et al., 2011]. Thus the density profile will correspond to the average flyby temperature that is $12 \mathrm{~K}$ hotter than the T40 flyby. Ideally we would use the INMS minor neutrals from the same flyby, however this data is not currently available. We utilize the Magee et al. [2009] values because they separate the $\mathrm{C}_{2} \mathrm{H}_{2}$ from the $\mathrm{C}_{2} \mathrm{H}_{4}$ while $\mathrm{Cui}$ et al. [2009] treat these as a combined species and the Magee et al. [2009] analysis includes HCN that, as will be discussed below, is crucial to evaluating the $\mathrm{HCNH}^{+}$density. Furthermore, Robertson et al. [2009] investigated the effects of using the Magee et al. [2009] versus the Cui et al. [2009] mixing ratios and found that the differences are small. by

[24] The ion-neutral reaction production and loss is given

$$
\begin{gathered}
P_{i}^{I-N}=\sum_{j} k_{j}\left[I_{j}\right]\left[n_{j}\right] \\
L_{i}^{I-N}=\sum_{j} k_{j}\left[n_{j}\right],
\end{gathered}
$$

where $k_{j}$ is the ion neutral reaction rate, $I_{j}$ is the reactant ion density, and $n_{j}$ is the reactant neutral density. The reactions used come from the model of Vuitton et al. [2007] with the additional reactions of methylenimine $\left(\mathrm{CH}_{2} \mathrm{NH}\right)$, propionitrile $\left(\mathrm{C}_{2} \mathrm{H}_{5} \mathrm{CN}\right)$, and benzene measured by Edwards et al. [2008] and Zabka et al. [2009]. A diagram of the primary chemical processes is shown in Figure 5.

[25] Loss due to electron recombination is given by

$$
L_{i}^{E R}=\alpha_{i}\left(\frac{300}{T_{e}}\right)^{\beta_{i}}\left[n_{e}\right]
$$

where $\alpha_{i}$ and $\beta_{i}$ are parameters of the reaction rate, $T_{e}$ is the electron temperature and $n_{e}$ is the electron density. The values of $\alpha_{i}$ and $\beta_{i}$ are from the list compiled by Vuitton et al. [2007] with updated recombination coefficients for temperatures between $180 \mathrm{~K}$ and $600 \mathrm{~K}$ for $\mathrm{HCNH}^{+}, \mathrm{CH}_{3} \mathrm{CNH}^{+}$, and $\mathrm{C}_{3} \mathrm{H}_{5} \mathrm{NH}^{+}$[McLain and Adams, 2009], updated constants for $\mathrm{CH}_{5}^{+}, \mathrm{C}_{2} \mathrm{H}_{5}^{+}$, and $\mathrm{C}_{6} \mathrm{H}_{7}^{+}$[McLain et al., 2004], and new values for $\mathrm{C}_{3} \mathrm{H}_{3} \mathrm{NH}^{+}$[Vigren et al., 2009].

\section{Empirical Model}

[26] One-dimensional photochemical models have been shown, especially in the case of Titan where the chemistry is particularly complex, to have a rather large range of potential solutions depending on the uncertainties in the reaction rates [Carrasco et al., 2008a], branching ratios [Carrasco and Pernot, 2007], the neutral densities [Carrasco et al., 2007], and various other uncertainties in the model. These uncertainties generally propagate through the calculation in a non-linear fashion. We maintain that the 1-D photochemical model is the only way to approach self-consistency in the modeling, however we find that the propagated errors in the calculations are prohibitive in exploring the causes of discrepancies. It is possible to isolate the chemical processes by decoupling the chemistry and relying on an empirical modeling approach based on the INMS data. We produce the empirical model by setting the left hand side of equation (2) to zero, implying that the system is in chemical equilibrium, and solving for the ion density. This results in the following equation:

$$
n_{\text {ion }}=\frac{\sum k_{p}\left[P^{+}\right]\left[N_{p}\right]}{\alpha\left[N_{e}\right]+\sum k_{l}\left[N_{l}\right]},
$$

where $n_{i o n}$ is the density of the ion to be calculated, $k_{p, l}$ are the reaction rate coefficients with the subscript $\mathrm{p}$ denoting the production and 1 denoting the loss, $P^{+}$is the density of the ion involved in the production reaction, $\alpha$ is the electron recombination rate coefficient, $N_{e}$ is the electron density, and $N_{p, l}$ are the densities of the neutrals controlling the production or loss of the ion species. The ion densities used in the calculations are obtained from the INMS open source and CAPS-IBS measurements and used directly to calculate the densities. The value of $n_{\text {ion }}$ is then calculated at each INMS altitude point and compared to the measured INMS densities. This calculation has been used to determine rate constants for several reactions in Earth's ionosphere [see, e.g., Torr et al., 1980].

[27] The utility of the empirical model is to isolate ions that are produced several chemical steps after the initial ionization of $\mathrm{N}_{2}$ and $\mathrm{CH}_{4}$. For example $\mathrm{C}_{6} \mathrm{H}_{5}^{+}$is expected to be produced primarily through a reaction of $\mathrm{C}_{4} \mathrm{H}_{2}^{+}$and $\mathrm{C}_{2} \mathrm{H}_{4}$. However, the chemistry presented by Vuitton et al. [2007] in the current photochemical implementation cannot produce sufficient $\mathrm{C}_{4} \mathrm{H}_{2}^{+}$to match the INMS observations. This was 


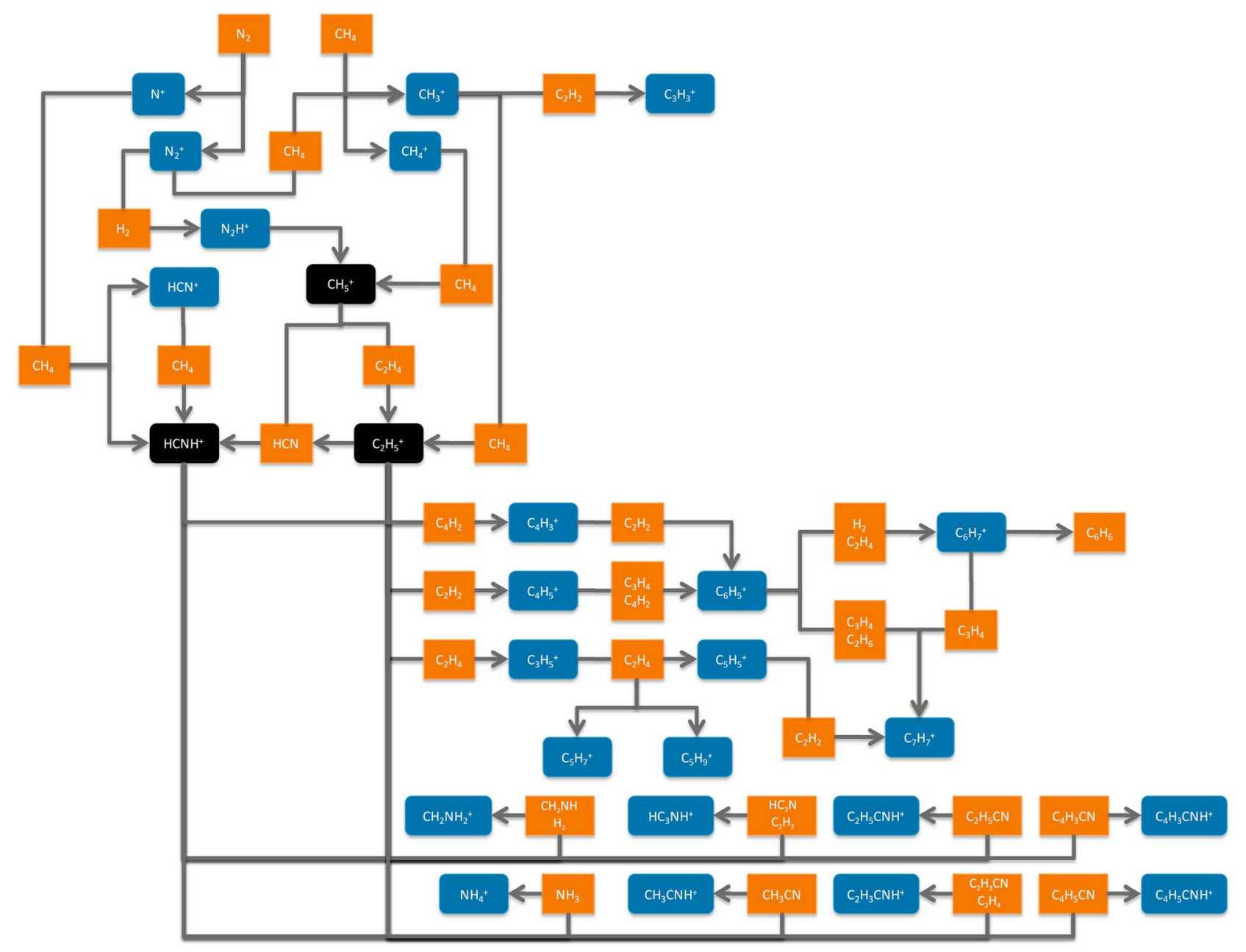

Figure 5. Shown are the primary ion-molecule reactions which take place in Titan's ionosphere. Neutral molecules are shown in orange, while ions are shown in blue. Reactions proceed following the arrows. From the ionization and dissociation of $\mathrm{N}_{2}$ and $\mathrm{CH}_{4}$ a host of hydrocarbons and nitrogen containing hydrocarbons are produced. The primary ionospheric ions $\mathrm{CH}_{5}^{+}, \mathrm{HCNH}^{+}$, and $\mathrm{C}_{2} \mathrm{H}_{5}^{+}$are shown in black. Two branches flow from the primary ions with the upper branch corresponding to the chemistry of Keller et al. [1998] and the lower branch corresponding to that of Vuitton et al. [2007].

noted by Vuitton et al. [2008] and dealt with by increasing the production rate of $\mathrm{C}_{4} \mathrm{H}_{2}^{+}$ten fold. Using our empirical model we can utilize the INMS observed densities for $\mathrm{C}_{4} \mathrm{H}_{2}^{+}$ to determine if the observed density is sufficient to produce $\mathrm{C}_{6} \mathrm{H}_{5}^{+}$. The ions that are produced using the 1-D photochemical model are subject to the errors of all of the previous ions in the chemical chain. To isolate the chemistry of a single ion without the propagated errors we use the empirical model.

\section{Results}

[28] In the following sections we compare both the photochemical model results and the empirical model results with the INMS ion data taken on the inbound leg of the T40 flyby. We display four versions of the models in the following sections, these different models are identified by the version of the electron temperature used and whether an additional $\mathrm{HCNH}^{+}$loss is included; these models are identified in Table 2 . We begin by analyzing the products of the solar photoionization and follow the chemistry through the INMS ion spectrum.

[29] To quantify the quality of the fitting to the INMS data we calculate a mean model-to-INMS ratio in the same way as Krasnopolsky [2009]. This ratio is calculated as

$$
F=\exp \left(\frac{1}{N} \sum_{i=1}^{N}\left|\ln \left(n_{\text {model }} / n_{I N M S}\right)\right|\right),
$$

Table 2. The Major Differences in the Four Different Model Runs Referred to in the Text

\begin{tabular}{lcl}
\hline & $\mathrm{T}_{e}$ & $\mathrm{HCNH}^{+}$Loss Process \\
\hline Model 1 & RPWS-LP & No \\
Model 2 & Richard et al. [2011] & No \\
Model 3 & RPWS-LP & Yes \\
Model 4 & Richard et al. $[2011]$ & Yes \\
\hline
\end{tabular}




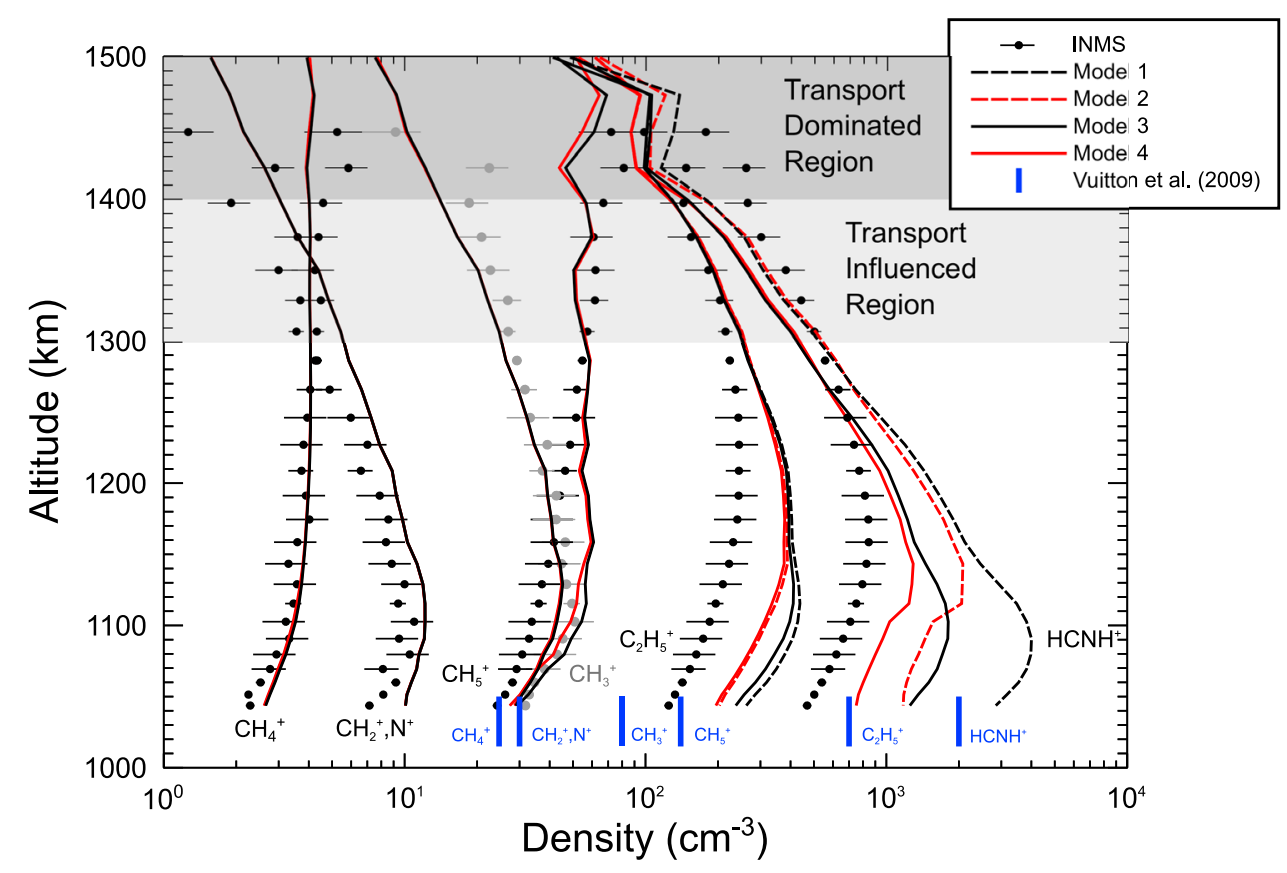

Figure 6. Shown are the results from the 1-D photochemical model compared to the INMS ion data. Model profiles are shown for the four different runs. The points show the INMS data from the mass 14, $15,16,17,28$, and 29 bins. The blue vertical bars show the model results of Vuitton et al. [2009a].

where $n_{\text {model }}$ and $n_{I N M S}$ are the modeled and observed ion densities and $N$ is the number of data points. $\mathrm{F}=1$ corresponds to a perfect fit to the data.

\subsection{Direct Products of the Photoionization of $\mathrm{CH}_{4}$ and $\mathbf{N}_{2}$}

[30] Methane and nitrogen in Titan's atmosphere are directly photoionized yielding $\mathrm{N}_{2}^{+}, \mathrm{N}^{+}, \mathrm{CH}_{4}^{+}, \mathrm{CH}_{3}^{+}, \mathrm{CH}_{2}^{+}$, $\mathrm{CH}^{+}, \mathrm{H}_{2}^{+}$, and $\mathrm{H}^{+}$. In the INMS ion data the most accessible tracers of direct ionization come from masses 14, 15, and 16 which correspond primarily to $\mathrm{N}^{+}, \mathrm{CH}_{3}^{+}$, and $\mathrm{CH}_{4}^{+}$respectively. The densities (points) obtained for mass 14, 15, and 16 are shown with the photochemically modeled profiles (lines) in Figure 6.

[31] The modeled $\mathrm{N}^{+}$and $\mathrm{CH}_{2}^{+}$profile is similar in shape to the mass 14 densities but overestimates the magnitude by $24 \%$ on average $(\mathrm{F}=1.27)$. The $\mathrm{CH}_{3}^{+}$and $\mathrm{CH}_{4}^{+}$profiles deviate from the INMS ion density measurements by $13 \%$ $(\mathrm{F}=1.17)$ and $1 \%(\mathrm{~F}=1.10)$, respectively. $\mathrm{CH}_{4}^{+}$is largely produced through photoionization of $\mathrm{CH}_{4}(73 \%)$ while $\mathrm{CH}_{3}^{+}$is primarily produced through the fast reactions

$$
\begin{gathered}
\mathrm{N}_{2}+h \nu \rightarrow \mathrm{N}_{2}^{+}+e^{-} \\
\mathrm{N}_{2}^{+}+\mathrm{CH}_{4} \rightarrow \mathrm{CH}_{3}^{+}+\mathrm{N}_{2}+\mathrm{H} .
\end{gathered}
$$

$\mathrm{CH}_{3}^{+}$is therefore the best tracer of $\mathrm{N}_{2}^{+}$photoionization [Cravens et al., 2009]. The production rates for $\mathrm{N}_{2}^{+}, \mathrm{N}^{+}$, $\mathrm{CH}_{3}^{+}$, and $\mathrm{CH}_{4}^{+}$are shown in Figure 7. The photoionization production rates obtained by this model are very similar to the rates reported by Lavvas et al. [2011] and Robertson et al. [2009].

[32] $\mathrm{N}^{+}, \mathrm{CH}_{2}^{+}, \mathrm{CH}_{3}^{+}$, and $\mathrm{CH}_{4}^{+}$are lost primarily through ion-molecule reactions with methane. In general these profiles correspond well to the INMS data indicating that the primary ion production from the photoionization of $\mathrm{N}_{2}$ and $\mathrm{CH}_{4}$ is well understood and accurately simulated in the model. At altitudes above about $1300 \mathrm{~km}$ ion transport is expected to become important [Cravens et al., 2006] and thus this model is not expected to accurately simulate the ion densities in this region, though for this particular flyby the 1-D photochemical model is reasonably accurate past this point. The simulated densities are in agreement with the measurements well above $1300 \mathrm{~km}$ indicating that transport may not be important for these species in this altitude range. This is expected as the ion-neutral reaction timescale is significantly faster than the transport timescale for these ions [Cravens et al., 2009]. From this we have a firm foundation that we can build upon for the production of the remainder of the ions simulated in the model.

[33] It is important to note that since these ions are lost primarily through ion-molecule reactions they are not dependent upon the electron recombination parameters such as the electron temperature and density. Therefore, the results from the four different versions of the photochemical model do not differ. The accurate production of these profiles indicates several pieces of the model are correctly implemented including the methane, acetylene, and ethylene densities that then contribute to the production of the major ions $\mathrm{CH}_{5}^{+}, \mathrm{C}_{2} \mathrm{H}_{5}^{+}$, and $\mathrm{HCNH}^{+}$. Also, the attenuation of the solar flux in the upper atmosphere is accurately represented in this model.

\subsection{The Major Ions $\mathrm{CH}_{5}^{+}, \mathrm{C}_{2} \mathrm{H}_{5}^{+}$, and $\mathrm{HCNH}^{+}$}

[34] These three ions are generally referred to as the major ions in Titan's ionosphere primarily due to their high abundances, but also due to their influence on the chemistry of the other ions. During the T40 flyby at the peak ionospheric 


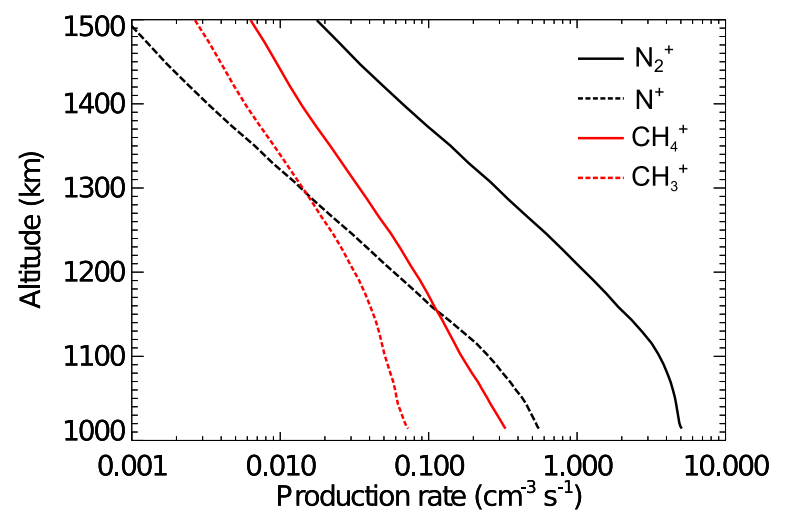

Figure 7. Shown are the modeled photoionization production rates for $\mathrm{N}_{2}^{+}, \mathrm{N}^{+}, \mathrm{CH}_{3}^{+}$, and $\mathrm{CH}_{4}^{+}$.

altitude near $1150 \mathrm{~km}$ these ions make up $65 \%$ of the total ion signal measured by the INMS, with roughly $2 \%$ from mass 17 (mostly $\mathrm{CH}_{5}^{+}$), 14\% from mass 29 (mostly $\mathrm{C}_{2} \mathrm{H}_{5}^{+}$), and $50 \%$ from mass 28 (mostly $\mathrm{HCNH}^{+}$). We study these ions as a group because their densities are tightly intertwined through the sequence of reactions

$$
\begin{gathered}
\mathrm{CH}_{5}^{+}+\mathrm{C}_{2} \mathrm{H}_{4} \rightarrow \mathrm{C}_{2} \mathrm{H}_{5}^{+}+\mathrm{CH}_{4}, \\
\mathrm{CH}_{5}^{+}+\mathrm{HCN} \rightarrow \mathrm{HCNH}^{+}+\mathrm{CH}_{4}, \\
\mathrm{C}_{2} \mathrm{H}_{5}^{+}+\mathrm{HCN} \rightarrow \mathrm{HCNH}^{+}+\mathrm{C}_{2} \mathrm{H}_{4} .
\end{gathered}
$$

Hence, any errors in the calculation of the $\mathrm{CH}_{5}^{+}$densities will influence the calculated density of $\mathrm{C}_{2} \mathrm{H}_{5}^{+}$and $\mathrm{HCNH}^{+}$ and vice versa. The primary controls on the densities of these three ions are the electron recombination parameters, minor neutral densities (primarily $\mathrm{HCN}$ and to a lesser extent $\mathrm{C}_{2} \mathrm{H}_{2}$ and $\mathrm{C}_{2} \mathrm{H}_{4}$ ), and the ion-molecule reaction scheme. In the following analysis we attempt to determine the major processes controlling the production and loss of these three major ions.

[35] Table 3 shows the primary production and loss processes for $\mathrm{HCNH}^{+}$. This ion is completely produced through ion-molecule reactions and is lost through a combination of ion-molecule and electron recombination reactions. There are a limited set of potential culprits for the model overestimation which we identify as (1) errors in the neutral atmospheric densities, (2) errors in the electron density, (3) errors in the electron temperature, (4) incorrect electron recombination coefficients, (5) incorrect reaction rate coefficients, and (6) missing loss processes. In the following analysis we will isolate each of these potential issues and determine to what extent they can contribute to the overestimation of $\mathrm{HCNH}^{+}$.

[36] Uncertainties in the neutral atmosphere can contribute greatly to the uncertainty in the model. Reactions with $\mathrm{HCN}$ are responsible for the majority of the production, hence the $\mathrm{HCN}$ mixing ratio is of great importance. The HCN mixing ratio of $(2.44 \pm 0.10) \times 10^{-4}$ given by Magee et al. [2009] at $1050 \mathrm{~km}$ has a statistical error of $4 \%$. Changing the $\mathrm{HCN}$ mixing ratio within this $4 \%$ error bar has the effect of changing the resultant $\mathrm{HCNH}^{+}$density by up to $3.6 \%$, a result which is far too small to explain the nearly $50 \%$ overestimation in the model. De La Haye et al. [2008] calculates diurnal $\mathrm{HCN}$ variations significantly greater than the statistical errors quoted by Magee et al. [2009]. For TA conditions the $\mathrm{HCN}$ mixing ratio is expected to range from $3 \times 10^{-4}$ to $7 \times 10^{-4}$ and for the T5 conditions it is expected to range from $8 \times 10^{-4}$ to $3 \times 10^{-3}$ allowing for a large range of acceptable values. However, increasing the $\mathrm{HCN}$ mixing

\begin{tabular}{|c|c|c|c|}
\hline Reaction & Rate Constant $\left(\mathrm{cm}^{-3} \mathrm{~s}^{-1}\right)$ & $\begin{array}{c}\text { Contribution } \\
\text { (Models } 1 \text { and 2) (\%) }\end{array}$ & $\begin{array}{c}\text { Contribution } \\
\text { (Models } 3 \text { and 4) (\%) }\end{array}$ \\
\hline \multicolumn{4}{|c|}{ Production Processes } \\
\hline $\mathrm{CH}_{4}^{+}+\mathrm{HCN} \rightarrow \mathrm{HCNH}^{+}+\mathrm{CH}_{3}$ & $k=3.2 \times 10^{-9} \mathrm{~cm}^{3} \mathrm{~s}^{-1}$ & 1 & 1 \\
\hline $\mathrm{CH}_{5}^{+}+\mathrm{HCN} \rightarrow \mathrm{HCNH}^{+}+\mathrm{CH}_{4}$ & $k=3.0 \times 10^{-9} \mathrm{~cm}^{3} \mathrm{~s}^{-1}$ & 14 & 14 \\
\hline $\mathrm{C}_{2} \mathrm{H}_{3}^{+}+\mathrm{HCN} \rightarrow \mathrm{HCNH}^{+}+\mathrm{C}_{2} \mathrm{H}_{2}$ & $k=2.3 \times 10^{-9} \mathrm{~cm}^{3} \mathrm{~s}^{-1}$ & 6 & 6 \\
\hline $\mathrm{C}_{2} \mathrm{H}_{5}^{+}+\mathrm{HCN} \rightarrow \mathrm{HCNH}^{+}+\mathrm{C}_{2} \mathrm{H}_{4}$ & $k=2.7 \times 10^{-9} \mathrm{~cm}^{3} \mathrm{~s}^{-1}$ & 61 & 61 \\
\hline $\mathrm{N}^{+}+\mathrm{CH}_{4} \rightarrow \mathrm{HCNH}^{+}+\mathrm{H}_{2}$ & $k=8.2 \times 10^{-11} \mathrm{~cm}^{3} \mathrm{~s}^{-1}$ & 2 & 2 \\
\hline $\mathrm{N}_{2} \mathrm{H}^{+}+\mathrm{HCN} \rightarrow \mathrm{HCNH}^{+}+\mathrm{N}_{2}$ & $k=3.2 \times 10^{-9} \mathrm{~cm}^{3} \mathrm{~s}^{-1}$ & 7 & 7 \\
\hline $\mathrm{HCN}^{+}+\mathrm{CH}_{4} \rightarrow \mathrm{HCNH}^{+}+\mathrm{CH}_{3}$ & $k=1.1 \times 10^{-9} \mathrm{~cm}^{3} \mathrm{~s}^{-1}$ & 3 & 3 \\
\hline $\mathrm{HNC}^{+}+\mathrm{CH}_{4} \rightarrow \mathrm{HCNH}^{+}+\mathrm{CH}_{3}$ & $k=1.1 \times 10^{-9} \mathrm{~cm}^{3} \mathrm{~s}^{-1}$ & 3 & 3 \\
\hline \multicolumn{4}{|c|}{ Loss Processes } \\
\hline $\mathrm{HCNH}^{+}+\mathrm{C}_{4} \mathrm{H}_{2} \rightarrow \mathrm{C}_{4} \mathrm{H}_{3}^{+}+\mathrm{HCN}$ & $k=1.8 \times 10^{-9} \mathrm{~cm}^{3} \mathrm{~s}^{-1}$ & 9 & 3 \\
\hline $\mathrm{HCNH}^{+}+\mathrm{C}_{6} \mathrm{H}_{2} \rightarrow \mathrm{C}_{6} \mathrm{H}_{3}^{+}+\mathrm{HCN}$ & $k=3.0 \times 10^{-9} \mathrm{~cm}^{3} \mathrm{~s}^{-1}$ & 3 & 1 \\
\hline $\mathrm{HCNH}^{+}+{ }_{c} \mathrm{C}_{6} \mathrm{H}_{6} \rightarrow \mathrm{C}_{6} \mathrm{H}_{7}^{+}+\mathrm{HCN}$ & $k=1.1 \times 10^{-9} \mathrm{~cm}^{3} \mathrm{~s}^{-1}$ & 4 & 1 \\
\hline $\mathrm{HCNH}^{+}+\mathrm{C}_{8} \mathrm{H}_{2} \rightarrow \mathrm{C}_{8} \mathrm{H}_{3}^{+}+\mathrm{HCN}$ & $k=3.0 \times 10^{-9} \mathrm{~cm}^{3} \mathrm{~s}^{-1}$ & 1 & 0.3 \\
\hline $\mathrm{HCNH}^{+}+\mathrm{NH}_{3} \rightarrow \mathrm{NH}_{4}^{+}+\mathrm{HCN}$ & $k=2.3 \times 10^{-9} \mathrm{~cm}^{3} \mathrm{~s}^{-1}$ & 1 & 0.4 \\
\hline $\mathrm{HCNH}^{+}+\mathrm{CH}_{2} \mathrm{NH} \rightarrow \mathrm{CH}_{2} \mathrm{NH}_{2}^{+}+\mathrm{HCN}$ & $k=2.7 \times 10^{-9} \mathrm{~cm}^{3} \mathrm{~s}^{-1}$ & 7 & 2 \\
\hline $\mathrm{HCNH}^{+}+\mathrm{C}_{3} \mathrm{H}_{3} \mathrm{~N} \rightarrow \mathrm{C}_{3} \mathrm{H}_{3} \mathrm{NH}^{+}+\mathrm{HCN}$ & $k=4.5 \times 10^{-9} \mathrm{~cm}^{3} \mathrm{~s}^{-1}$ & 2 & 0.5 \\
\hline$H C N H^{+}+H_{3} N \rightarrow H C_{3} N H^{+}+H C N$ & $k=3.4 \times 10^{-9} \mathrm{~cm}^{3} \mathrm{~s}^{-1}$ & 5 & 2 \\
\hline $\mathrm{HCNH}^{+}+\mathrm{C}_{4} \mathrm{H}_{3} \mathrm{~N} \rightarrow \mathrm{C}_{4} \mathrm{H}_{3} \mathrm{NH}^{+}+\mathrm{HCN}$ & $k=3.0 \times 10^{-9} \mathrm{~cm}^{3} \mathrm{~s}^{-1}$ & 13 & 4 \\
\hline $\mathrm{HCNH}^{+}+\mathrm{HC}_{5} \mathrm{~N} \rightarrow \mathrm{HC}_{5} \mathrm{NH}^{+}+\mathrm{HCN}$ & $k=3.0 \times 10^{-9} \mathrm{~cm}^{3} \mathrm{~s}^{-1}$ & 4 & 1 \\
\hline $\mathrm{HCNH}^{+}+\mathrm{C}_{5} \mathrm{H}_{5} \mathrm{~N} \rightarrow \mathrm{C}_{5} \mathrm{H}_{5} \mathrm{NH}^{+}+\mathrm{HCN}$ & $k=3.0 \times 10^{-9} \mathrm{~cm}^{3} \mathrm{~s}^{-1}$ & 2 & 0.5 \\
\hline $\mathrm{HCNH}^{+}+\mathrm{C}_{6} \mathrm{H}_{3} \mathrm{~N} \rightarrow \mathrm{C}_{6} \mathrm{H}_{3} \mathrm{NH}^{+}+\mathrm{HCN}$ & $k=3.0 \times 10^{-9} \mathrm{~cm}^{3} \mathrm{~s}^{-1}$ & 1 & 0.5 \\
\hline HCNH + Unknown $\rightarrow$ Unknown & $k=$ Unknown $\mathrm{cm}^{3} \mathrm{~s}^{-1}$ & 0 & 67 \\
\hline $\mathrm{HCNH}^{+}+e^{-} \rightarrow$ products & $3.5 \times 10^{-7}\left(\frac{300}{T_{e}}\right)^{1.38}\left[n_{e}\right]$ & 47 & 15 \\
\hline
\end{tabular}
ratio has the effect of increasing the $\mathrm{HCNH}^{+}$density while

Table 3. The Processes Responsible for the Production and Loss of $\mathrm{HCNH}^{+}$ 


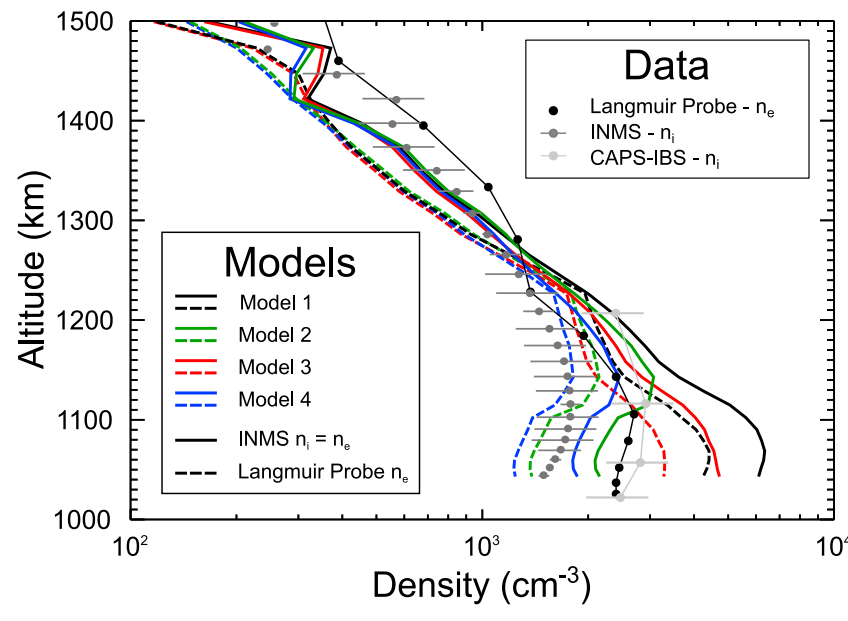

Figure 8. The total electron and ion density observed by the LP, INMS, and CAPS-IBS during the inbound leg of the T40 flyby. The model profiles represent four model runs with different total electron densities and electron temperatures. The dashed profiles are produced by the 1-D photochemical model using the LP total electron density while the solid profiles use the INMS ion density as equal to the total electron density. The colors correspond to the four different models identified in Table 2.

decreasing the $\mathrm{CH}_{5}^{+}$and $\mathrm{C}_{2} \mathrm{H}_{5}^{+}$densities and decreasing the $\mathrm{HCN}$ mixing ratio has the inverse effect. Therefore, decreasing the $\mathrm{HCN}$ mixing ratio will improve the $\mathrm{HCNH}^{+}$density profile at the expense of the $\mathrm{CH}_{5}^{+}$and $\mathrm{C}_{2} \mathrm{H}_{5}^{+}$density profiles. We conclude that this cannot be the solution to the $\mathrm{HCNH}^{+}$ overestimation as improvements in the $\mathrm{HCNH}^{+}$density profiles come at the cost of the other major ion profiles. Reactions with methane contribute to $8 \%$ of the $\mathrm{HCNH}^{+}$production and are unlikely to yield significant enough effects to reduce the overestimation. We therefore conclude that the neutral atmosphere used in the model is not at the root of the $\mathrm{HCNH}^{+}$overestimation.

[37] Electron recombination contributes to $47 \%$ of the overall loss of $\mathrm{HCNH}^{+}$. Equation (6) shows that the electron recombination rate is dependent on the electron temperature and density. In general it is assumed that the electron density is equal to the ion density throughout this region of the ionosphere, implying that no significant currents or flows are present. This has been confirmed by Wahlund et al. [2009] through a multi-instrument analysis of several Cassini flybys. In general below $1400 \mathrm{~km}$ and above about $1100 \mathrm{~km}$ the total ion density measured by the Cassini INMS is equal to the total electron density measured by the Cassini Radio and Wave Plasma Science Langmuir Probe (LP). Above this region the ions and electrons exhibit significant flows that will negatively affect the ability of the INMS to observe the ions [Cravens et al., 2005], while below this region ions beyond the INMS mass range become important [Wahlund et al., 2009; Waite et al., 2007]. The total electron and ion densities observed by the LP, INMS, and CAPS-IBS are presented in Figure 8. The total ion and electron densities observed during this flyby are nearly equal over the altitude range of 1150 to $1500 \mathrm{~km}$. Below this the densities diverge with the total electron density being up to $27 \%$ greater than the total ion density. We have also plotted the total ion density observed by the CAPS-IBS during the flyby. There is a significant deviation from the CAPS-IBS and the INMS densities, most of which can be attributed to large ions past the mass range of the INMS. Also shown are model runs using different total electron densities. The dashed profiles correspond to the model runs using the LP total electron density in equation (6) while the solid profiles are calculated assuming that the total observed ion density by the INMS is equal to the total electron density. The use of different total electron densities has a substantial effect on the modeled densities.

[38] The other variable in the electron recombination rate is the electron temperature $\left(T_{e}\right)$. The LP retrieved electron temperatures are shown beside the modeled electron temperatures of Richard et al. [2011] for conditions similar to those observed for T40 in Figure 9. These electron temperatures are similar at altitudes above about $1200 \mathrm{~km}$, however below $1200 \mathrm{~km}$ they differ by about a factor of 3 . As the electron temperature decreases the loss rate will increase resulting in less $\mathrm{HCNH}^{+}$, therefore the temperatures of Richard et al. [2011] result in less $\mathrm{HCNH}^{+}$than the LP derived values especially at the lowest altitudes. The total photochemically modeled densities are shown in Figure 8 using the LP electron temperatures and using electron temperatures from Richard et al. [2011]. The different electron temperatures produce a $66 \%$ difference between the two models at $1050 \mathrm{~km}$. This difference is significantly greater than the difference observed when changing the electron densities. The electron temperature is highly dependent on the photoelectron spectrum, incident energy fluxes, and the magnetic field configuration. Studies of these influences are beyond the scope of this work, however the electron temperatures are of great importance for modeling the ionospheric densities.

[39] Also important when considering the electron recombination process are the laboratory measured rate coefficients. There have been two laboratory measurements of the

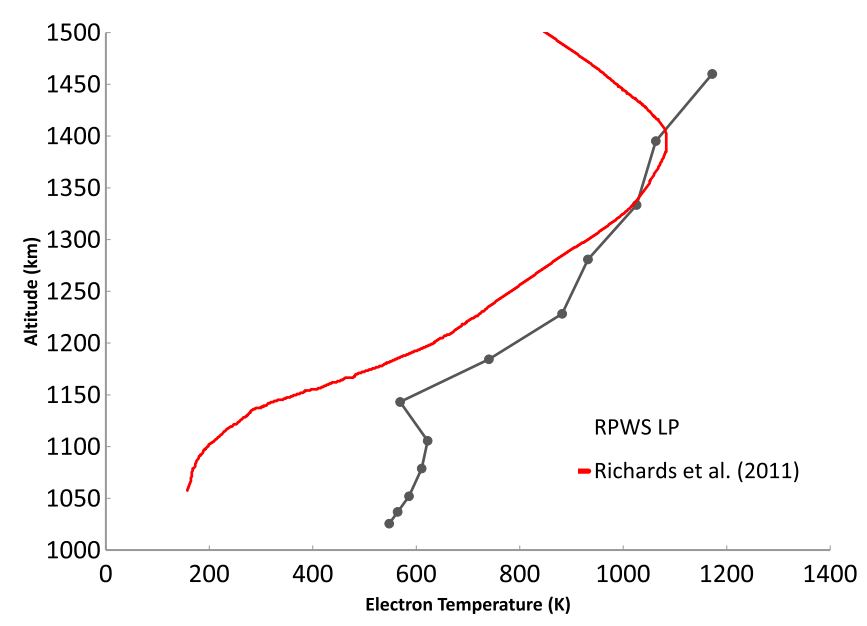

Figure 9. The electron temperatures used for this model. The LP values are shown in the black points with the lines connecting the points while the calculated electron temperatures of Richard et al. [2011] are shown in grey. The modeled electron temperatures of Richard et al. [2011] are lower than the LP values below about $1200 \mathrm{~km}$ and approach the neutral temperature at the lowest altitudes. 


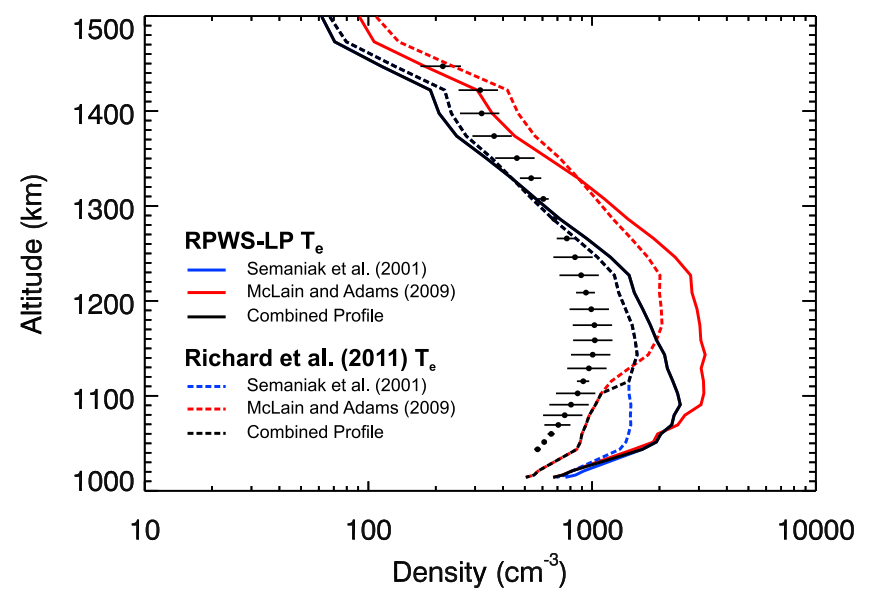

Figure 10. The calculated $\mathrm{HCNH}^{+}$densities using various measured electron recombination rates. Two groups of profiles are shown, the solid profiles reflect densities obtained using the RPWS-LP $\mathrm{T}_{e}$ while the dashed profiles give the densities obtained using the Richard et al. [2011] $\mathrm{T}_{e}$. The combination profiles are obtained using the McLain and Adams [2009] recombination rate for $\mathrm{T}_{e}$ less than $300 \mathrm{~K}$ and the Semaniak et al. [2001] rate for $\mathrm{T}_{e}$ greater than $300 \mathrm{~K}$.

electron recombination rate for $\mathrm{HCNH}^{+}$. Semaniak et al. [2001] gives a value for $\alpha$ of $2.8 \times 10^{-7} \mathrm{~cm}^{3} \mathrm{~s}^{-1}$ and 0.65 for $\beta$ in equation (6) applicable for electron temperatures below 1000 K. McLain and Adams [2009] gives an $\alpha$ coefficient of $3.5 \times 10^{-7}$ and a temperature coefficient $(\beta)$ of 1.38 for electron temperatures between $150 \mathrm{~K}$ and $600 \mathrm{~K}$. This modification produces a greater electron recombination rate at electron temperatures less than about $400 \mathrm{~K}$, and a lower rate at greater electron temperatures. For example at $150 \mathrm{~K}$ the electron recombination coefficient calculated from the work of Semaniak et al. [2001] yields a rate coefficient of $4.39 \times 10^{-7} \mathrm{~cm}^{3} \mathrm{~s}^{-1}$ while the rate from the work of McLain and Adams [2009] yields a rate of $9.11 \times 10^{-7} \mathrm{~cm}^{3} \mathrm{~s}^{-1}$ which is more than a factor of two difference. This means that for the lowest altitudes, where the electron temperature declines, the loss rate for $\mathrm{HCNH}^{+}$will be greater than previously expected. We incorporate the McLain and Adams [2009] values up to $300 \mathrm{~K}$ where they diverge from the Semaniak et al. [2001] values. The difference between adopting either of the individual measurements versus making the transition between the two measurements at $300 \mathrm{~K}$ is substantial as evidenced by Figure 10 .

[40] We have now discussed items $1-5$ on our list of possible contributors to the $\mathrm{HCNH}^{+}$overestimation finding that the electron temperature has the greatest effect so far, but cannot completely solve the problem. We therefore turn to missing loss processes in the chemistry. The reactions of $\mathrm{HCNH}^{+}$with $\mathrm{H}_{2}, \mathrm{C}_{2} \mathrm{H}_{2}, \mathrm{C}_{2} \mathrm{H}_{4}, \mathrm{C}_{2} \mathrm{H}_{6}, \mathrm{C}_{4} \mathrm{H}_{2}, \mathrm{NH}_{3}, \mathrm{HC}_{3} \mathrm{~N}$, $\mathrm{H}_{2} \mathrm{O}, \mathrm{CH}_{3} \mathrm{NH}_{2}, \mathrm{CH}_{2} \mathrm{NH}, \mathrm{C}_{2} \mathrm{H}_{5} \mathrm{CN}$ have been studied in the laboratory [Anicich and McEwan, 1997; Edwards et al., 2008]. The most likely reaction type found was the proton exchange channel. However, in one case an association product was found which is identified at Titan, namely the reaction of $\mathrm{HCNH}^{+}$with $\mathrm{C}_{2} \mathrm{H}_{4}$ produced $\mathrm{C}_{2} \mathrm{H}_{5} \mathrm{NCH}^{+}$ [Wilson et al., 1993]. The studies of the reactions of $\mathrm{HCNH}^{+}$ with the other $\mathrm{C} 2$ hydrocarbons were performed at high pressures where termolecular processes dominate [Herbst et al., 1989]. We have no laboratory data about the propensity of $\mathrm{HCNH}^{+}$to react with $\mathrm{H}_{2}, \mathrm{C}_{2} \mathrm{H}_{2}$, or $\mathrm{C}_{2} \mathrm{H}_{4}$ at pressures and temperatures relevant to Titan's ionosphere. We therefore consider each possibility. We neglect other hydrocarbons and nitrogen containing hydrocarbons as their densities are too small to be effective reactants. In considering these reactions we pose an alternate hypothesis to that of Vuitton et al. [2006], namely that the nitrogen containing hydrocarbons $\mathrm{CH}_{2} \mathrm{NH}_{2}^{+}, \mathrm{C}_{3} \mathrm{H}_{4} \mathrm{~N}^{+}$, and $\mathrm{C}_{3} \mathrm{H}_{6} \mathrm{~N}^{+}$are not produced through proton exchange reactions but through the following ion-molecule reactions:

$$
\begin{gathered}
\mathrm{HCNH}^{+}+\mathrm{H}_{2} \rightarrow \mathrm{CH}_{2} \mathrm{NH}_{2}^{+}, \\
\mathrm{HCNH}^{+}+\mathrm{C}_{2} \mathrm{H}_{2} \rightarrow \mathrm{HC}_{3} \mathrm{NH}^{+}+\mathrm{H}_{2}, \\
\mathrm{HCNH}^{+}+\mathrm{C}_{2} \mathrm{H}_{4} \rightarrow \mathrm{C}_{3} \mathrm{H}_{3} \mathrm{NH}^{+}+\mathrm{H}_{2} .
\end{gathered}
$$

These reactions could be stabilized either through radiative or collisional processes. At the temperatures and pressures of Titan's ionosphere it is more likely to find radiative stabilization. Reaction 14 was studied theoretically by Herbst [1976] who calculated a range of rate coefficients for the production of a long-lived complex $\left(\mathrm{CH}_{2} \mathrm{NH}_{2}^{+}\right)^{*}$ from $5.0 \times 10^{-11} \mathrm{~cm}^{3} \mathrm{~s}^{-1}$ to $1.5 \times 10^{-9} \mathrm{~cm}^{3} \mathrm{~s}^{-1}$, and a range of total rate coefficients for the production of $\mathrm{CH}_{2} \mathrm{NH}_{2}^{+}$of $9.1 \times 10^{-15} \mathrm{~cm}^{3} \mathrm{~s}^{-1}$ to $2.7 \times 10^{-13} \mathrm{~cm}^{3} \mathrm{~s}^{-1}$.

[41] Figure 11 shows in grey the resulting profiles when reactions of $\mathrm{HCNH}^{+}$with $\mathrm{H}_{2}, \mathrm{CH}_{4}, \mathrm{C}_{2} \mathrm{H}_{2}$, and $\mathrm{C}_{2} \mathrm{H}_{4}$ are individually inserted with reaction rates of $6 \times 10^{-11}$,

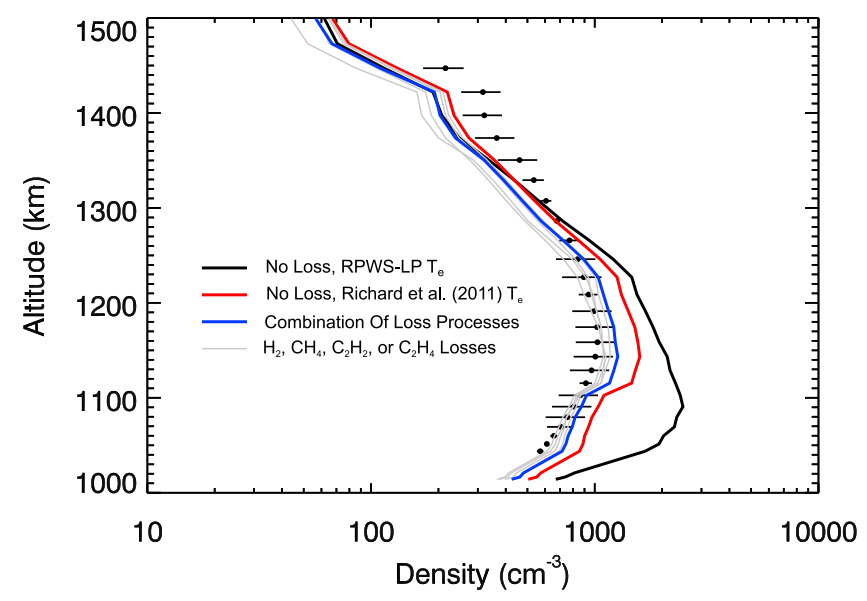

Figure 11. Shown are the density profiles for $\mathrm{HCNH}^{+}$ obtained using the empirical model with a theoretical loss process. The loss process is an ion-molecule reaction with the indicated neutral. The rate coefficients used are $6 \times 10^{-11}$, $1 \times 10^{-11}, 2 \times 10^{-10}, 2 \times 10^{-10}$ for $\mathrm{H}_{2}, \mathrm{CH}_{4}, \mathrm{C}_{2} \mathrm{H}_{2}$, and $\mathrm{C}_{2} \mathrm{H}_{4}$ respectively and the resulting density profiles are shown in grey. We also show the $\mathrm{HCNH}^{+}$profile calculated with no loss processes and the $\mathrm{LP}_{e}$ (black profile), no loss processes and the Richard et al. [2011] $\mathrm{T}_{e}$ (red profile), and a combination of $\mathrm{H}_{2}, \mathrm{C}_{2} \mathrm{H}_{2}$, and $\mathrm{C}_{2} \mathrm{H}_{4}$ reactions and the $\mathrm{LP}$ electron temperatures or the Richard et al. [2011] electron temperatures. 
Table 4. The Mixing Ratios at $1050 \mathrm{~km}$ Used for the 1-D Photochemical Model Runs

\begin{tabular}{lccc}
\hline Species & Models 1 and 2 & Models 3 and 4 & ${\text { Vuitton et al. }[2009 \mathrm{a}]^{\mathrm{a}}}^{\text {a }}$ \\
\hline $\mathrm{C}_{2} \mathrm{H}_{2}$ & $3.42 \times 10^{-4}$ & $3.42 \times 10^{-4}$ & $9.9 \times 10^{-4}$ \\
$\mathrm{C}_{2} \mathrm{H}_{4}$ & $3.91 \times 10^{-4}$ & $3.91 \times 10^{-4}$ & \\
$\mathrm{C}_{3} \mathrm{H}_{4}$ & $9.20 \times 10^{-6}$ & $9.20 \times 10^{-6}$ & \\
$\mathrm{C}_{4} \mathrm{H}_{2}$ & $5.55 \times 10^{-6}$ & $5.55 \times 10^{-6}$ & $1.1 \times 10^{-5}$ \\
$\mathrm{C}_{6} \mathrm{H}_{6}$ & $2.48 \times 10^{-6}$ & $2.48 \times 10^{-6}$ & \\
$\mathrm{NH}_{3}$ & $3.0 \times 10^{-7}$ & $5.0 \times 10^{-7}$ & \\
$\mathrm{HCN}$ & $2.44 \times 10^{-4}$ & $2.44 \times 10^{-4}$ & $1.9 \times 10^{-4}$ \\
$\mathrm{CH}_{2} \mathrm{NH}$ & $1.5 \times 10^{-6}$ & $3.0 \times 10^{-6}$ & \\
$\mathrm{CH}_{3} \mathrm{CN}$ & $2.0 \times 10^{-7}$ & $2.0 \times 10^{-7}$ & $9.9 \times 10^{-7}$ \\
$\mathrm{HC}_{3} \mathrm{~N}$ & $1.48 \times 10^{-6}$ & $1.48 \times 10^{-6}$ & $3.4 \times 10^{-5}$ \\
$\mathrm{C}_{2} \mathrm{H}_{3} \mathrm{CN}$ & $3.46 \times 10^{-7}$ & $3.46 \times 10^{-7}$ & $2.2 \times 10^{-6}$ \\
\hline
\end{tabular}

${ }^{\mathrm{a}}$ The values used by Vuitton et al. [2009a] scaled to $1050 \mathrm{~km}$.

$1 \times 10^{-11}, 2 \times 10^{-10}$, and $2 \times 10^{-10}$ respectively. As can be seen in the figure, the profiles are nearly identical. We also draw attention to the products of these reactions as they give a second independent measure of the appropriate reaction rate. The ultimate solution is likely to be some combination of these reactions resulting in lowered reaction rate coefficients. These reactions are not likely to be proton exchange reactions as $\mathrm{HCN}$ has a greater proton affinity than any of the proposed neutrals. Associative reaction channels would lead to the production of specific ions that we can test against the INMS data. If we consider that an association reaction occurs with $\mathrm{H}_{2}, \mathrm{C}_{2} \mathrm{H}_{2}$, and $\mathrm{C}_{2} \mathrm{H}_{4}$ producing $\mathrm{CH}_{2} \mathrm{NH}_{2}^{+}, \mathrm{HC}_{3} \mathrm{NH}^{+}$, and $\mathrm{C}_{3} \mathrm{H}_{3} \mathrm{NH}^{+}$we obtain the maximum rate constants of $2 \times 10^{-11}, 5 \times 10^{-11}$, and $6 \times 10^{-13}$ respectively. We obtain these maximum reaction rate coefficients by comparing the densities obtained from the empirical model using a range of rate coefficients and determining which rate coefficient best fits the measured $\mathrm{CH}_{2} \mathrm{NH}_{2}^{+}$, $\mathrm{HC}_{3} \mathrm{NH}^{+}$, and $\mathrm{C}_{3} \mathrm{H}_{3} \mathrm{NH}^{+}$densities. We note that these rate constants could be larger if other loss processes are found for the product ions. Using these three loss processes we obtain the combination loss profile shown in blue in Figure 11. These three processes taken together can account for a substantial loss of the $\mathrm{HCNH}^{+}$ion and result in sufficient production of $\mathrm{CH}_{2} \mathrm{NH}_{2}^{+}, \mathrm{HC}_{3} \mathrm{NH}^{+}$, and $\mathrm{C}_{3} \mathrm{H}_{3} \mathrm{NH}^{+}$to match the INMS data.

[42] Loss processes other than first order ion-molecule reactions are also possible. For example, it is likely that substantial densities of large hydrocarbon and nitrogencontaining hydrocarbon molecules exist below $1200 \mathrm{~km}$. These molecules are likely to be unsaturated in nature and will definitely have large proton affinities [Crary et al., 2009]. The assumed density of these molecules and their deviation with altitude is discussed in the companion paper (J. H. Westlake et al., Titan's ionospheric composition and structure: Large ion composition and growth, submitted to Journal of Geophysical Research, 2011). Here we note that significant amounts of large molecules are available for proton exchange reactions with these major ions and may produce the low altitude decrease in density needed to account for the excess density. However, due to the small expected scale height of the high mass neutrals it is not possible for this process to account for the missing high altitude loss process.

[43] Negative ions such as those observed by the CAPS-ELS [Coates et al., 2007] could act as a sink of the positive ions observed here. The rate coefficients are expected to be between $10^{-8}$ to $10^{-7} \mathrm{~cm}^{3} \mathrm{~s}^{-1}$. However, the density of these ions, which is at most $20 \%$ of the electron density [Coates et al., 2007], does not compare with the neutral densities used to calculate the ion-molecule reaction losses. For example, a loss process in which an ion reacts with methane at a rate coefficient of $10^{-10} \mathrm{~cm}^{3} \mathrm{~s}^{-1}$ would have a loss rate of roughly $0.1 \mathrm{~s}^{-1}$ assuming a methane density of $10^{9} \mathrm{~cm}^{-3}$. On the other hand the loss rate for a negative ion of density $200 \mathrm{~cm}^{-3}$ reacting with a positive ion at a rate of $10^{-7} \mathrm{~cm}^{3} \mathrm{~s}^{-1}$ would result in a loss rate of $2 \times 10^{-4} \mathrm{~s}^{-1}$. This loss rate is far too small to be of importance for any ion and is thus neglected. We do note however that the negative ions may be contributing to loss processes other than the positive ion-negative ion recombination.

[44] Modeling the major ions with appropriate densities allows for the accurate determination of the larger hydrocarbons and the further investigation of potential reaction pathways in the nitrogen-containing hydrocarbons. We now split the pathways into those consisting solely of hydrocarbons and those that contain nitrogen. While it is likely true that there is significant crossover between the two pathways through reactions of hydrocarbons with $\mathrm{N}, \mathrm{CN}$, and $\mathrm{HCN}$, this division provides a logical split that makes the chemical processes simpler to understand.

\subsection{The Major Hydrocarbon Pathways}

[45] The mixing ratios shown in Table 4 were used for the four models we have presented. The mixing ratios that are constant for all three models are those determined by the INMS neutral data from the study of Magee et al. [2009]. The others are varied such that the modeled density profile produces the best fit to the data.

[46] Figure 12 displays the results of Model 1 (dashed profiles) and Model 2 (solid profiles) for the minor hydrocarbons $\mathrm{C}_{2} \mathrm{H}_{3}^{+}, \mathrm{C}_{2} \mathrm{H}_{5}^{+}, \mathrm{C}_{3} \mathrm{H}_{3}^{+}, \mathrm{C}_{3} \mathrm{H}_{5}^{+}, \mathrm{C}_{4} \mathrm{H}_{3}^{+}, \mathrm{C}_{4} \mathrm{H}_{5}^{+}, \mathrm{C}_{5} \mathrm{H}_{5}^{+}$, $\mathrm{C}_{5} \mathrm{H}_{7}^{+}, \mathrm{C}_{6} \mathrm{H}_{5}^{+}$, and $\mathrm{C}_{6} \mathrm{H}_{7}^{+}$. The dashed profiles in the figure show the calculations made with the LP electron temperatures, while the solid profiles use the Richard et al. [2011] electron temperatures. In general, the profiles are in good correspondence with the data indicating that the major chemical processes are in place in the model. The LP electron temperatures generally overestimate the ion densities below $1100 \mathrm{~km}$, while the electron temperatures of Richard et al. [2011] tend to improve the correspondence. The calculated profiles for Models 3 and 4 are identical for most of these minor hydrocarbons as there are few major reactions tying $\mathrm{HCNH}^{+}$to these ions. The exception is $\mathrm{C}_{6} \mathrm{H}_{7}^{+}$which will be affected by the proton exchange reaction of $\mathrm{HCNH}^{+}$with $\mathrm{C}_{6} \mathrm{H}_{6}$.

[47] We consider the methane density to be a fixed constraint on the calculations because the densities come directly from INMS measurements with small uncertainties. Acetylene and ethylene on the other hand are only constrained at $1050 \mathrm{~km}$ by the analysis of Magee et al. [2009] in which the quoted uncertainties correspond to the uncertainty in the measurement and do not reflect any variation in the atmosphere. There has not been a global study of how the minor components vary in Titan's atmosphere, however the study of Cui et al. [2009] found some dependence of the acetylene and ethylene mixing ratios on latitude in the northern hemisphere. Any deviation in the neutral density profiles from the 

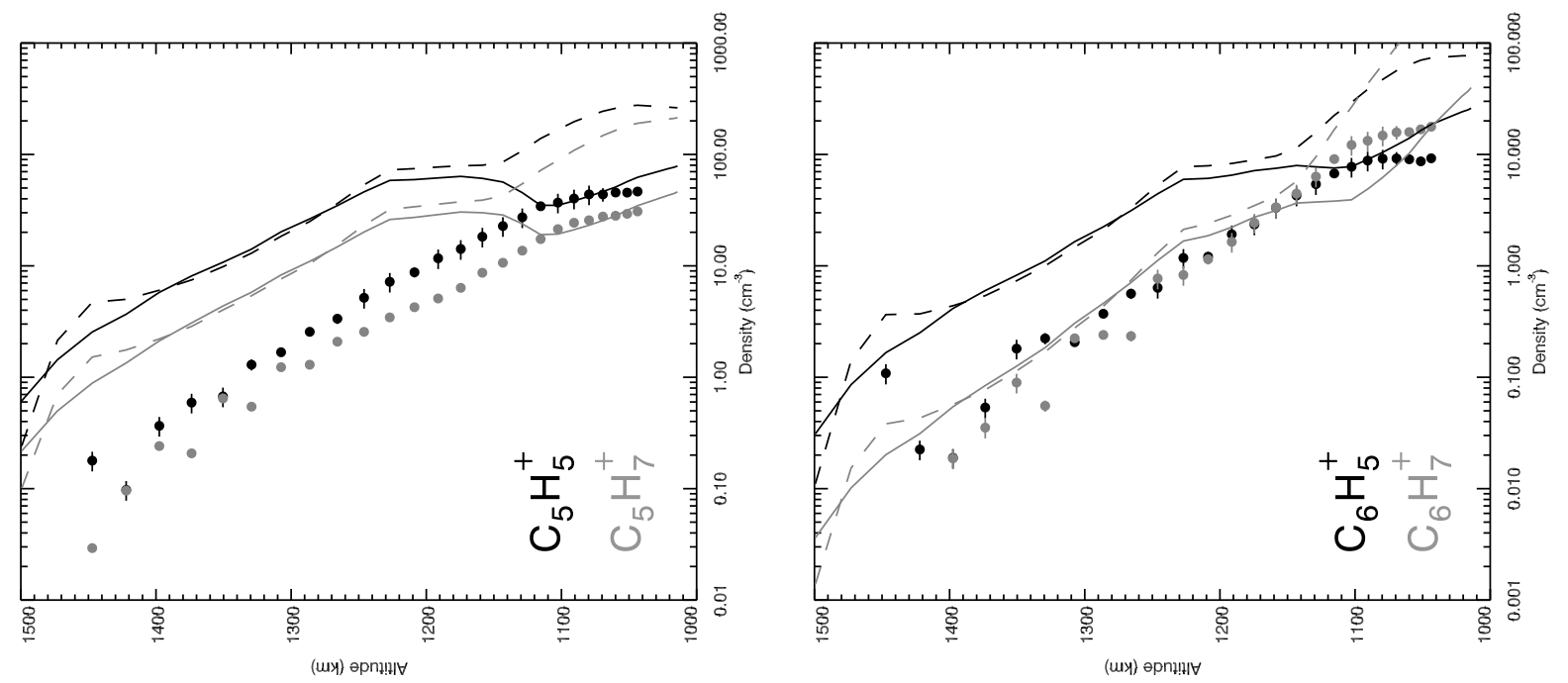

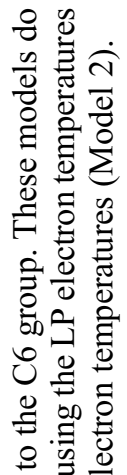
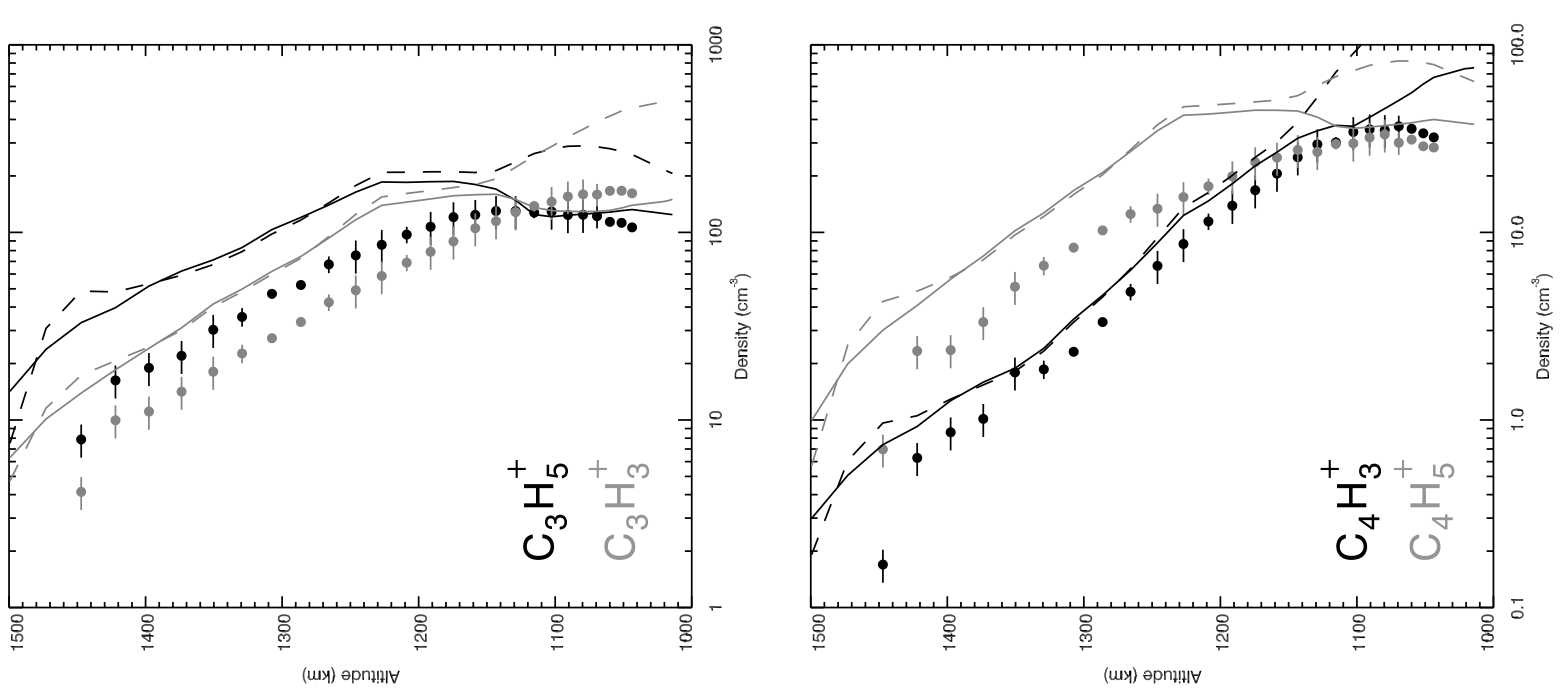

Oิ.

突官

घํำ

章

.

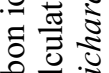

卷

읭

칭.

.흘

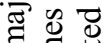

导浔

రิ)

ㅇ ㅇ

可.

要表

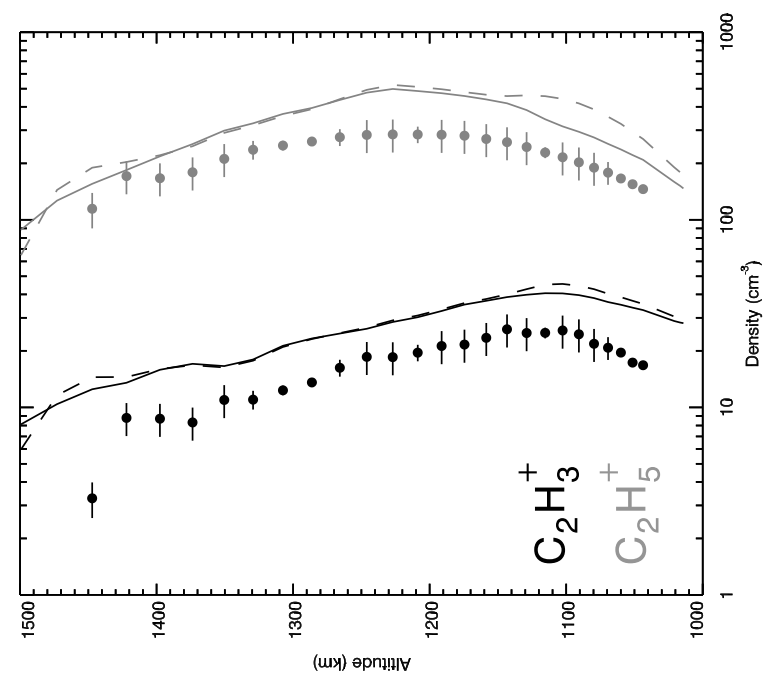


Table 5. The Processes Controlling the Production and Loss of the Minor Hydrocarbon Ions (\%)

\begin{tabular}{|c|c|c|c|c|c|c|c|c|c|c|}
\hline & $\mathrm{C}_{2} \mathrm{H}_{3}^{+}$ & $1-\mathrm{C}_{3} \mathrm{H}_{3}^{+}$ & c- $\mathrm{C}_{3} \mathrm{H}_{3}^{+}$ & $\mathrm{C}_{3} \mathrm{H}_{5}^{+}$ & $\mathrm{C}_{4} \mathrm{H}_{3}^{+}$ & $\mathrm{C}_{4} \mathrm{H}_{5}^{+}$ & $\mathrm{C}_{5} \mathrm{H}_{5}^{+}$ & $\mathrm{C}_{5} \mathrm{H}_{7}^{+}$ & $\mathrm{C}_{6} \mathrm{H}_{5}^{+}$ & $\mathrm{C}_{6} \mathrm{H}_{7}^{+}$ \\
\hline \multicolumn{11}{|c|}{ Production Processes } \\
\hline Primary Ion Reaction & 49 & 100 & 27 & 13 & 1 & 1 & 0 & 0 & 0 & 1 \\
\hline Major Ion Reaction & 35 & 0 & 22 & 34 & 67 & 80 & 0 & 0 & 0 & 77 \\
\hline Other Ion Reaction & 16 & 0 & 51 & 53 & 32 & 19 & 100 & 100 & 100 & 22 \\
\hline \multicolumn{11}{|c|}{ Loss Processes } \\
\hline Ion-Molecule Reaction & 96 & 97 & 0 & 49 & 59 & 43 & 25 & 2 & 73 & 1 \\
\hline Electron Recombination & 4 & 3 & 100 & 51 & 41 & 57 & 75 & 98 & 27 & 99 \\
\hline
\end{tabular}

background neutral model will significantly influence the derived ion profiles.

[48] Table 5 shows the processes controlling the production and loss of the minor hydrocarbons. The production of these ions comes entirely from ion-molecule reactions. For the smaller ions such as $\mathrm{C}_{2} \mathrm{H}_{3}^{+}$a majority of the production comes from the reactions with the primary ions $\mathrm{CH}_{3}^{+}, \mathrm{CH}_{4}^{+}$, $\mathrm{N}^{+}, \mathrm{N}_{2}^{+}$, and $\mathrm{N}_{2} \mathrm{H}^{+}$. For these smaller ions their direct tie to the primary ions results in better photochemical model results. The higher mass ions are dependent more on the major ions and their products (represented by the other ion reaction row). The propagated error in the densities of the major ions and their products negatively influences the model results. For many of these ions their primary losses come from ion-molecule reactions. The ions c- $\mathrm{C}_{3} \mathrm{H}_{3}^{+}, \mathrm{C}_{4} \mathrm{H}_{5}^{+}$, $\mathrm{C}_{5} \mathrm{H}_{5}^{+}, \mathrm{C}_{5} \mathrm{H}_{7}^{+}$, and $\mathrm{C}_{6} \mathrm{H}_{7}^{+}$are primarily lost through electron recombination and are therefore more influenced by the various electron temperatures used. These ions are also primarily produced through reactions with the major ions and their products resulting in enhanced propagated errors.

[49] Figure 13 shows the calculated density profiles from the empirical model that decouples the chemistry, effectively removing the propagated errors of the 1-D photochemical model. It is clear that the ions which are highly dependent on electron recombination have larger differences between the models presented, however, because the propagated errors are removed the densities of the ions which are controlled by ion-molecule reaction processes all match the measured densities better than the 1-D photochemical model results. This indicates that the chemical processes which produce these minor hydrocarbon ions are in place and that the issues with the 1-D photochemical model result primarily from propagated errors.

[50] We find from this study that the densities of the minor hydrocarbon ions $\mathrm{C}_{3} \mathrm{H}_{3}^{+}, \mathrm{C}_{3} \mathrm{H}_{4}^{+}, \mathrm{C}_{3} \mathrm{H}_{5}^{+}, \mathrm{C}_{4} \mathrm{H}_{3}^{+}, \mathrm{C}_{4} \mathrm{H}_{5}^{+}, \mathrm{C}_{5} \mathrm{H}_{5}^{+}$, $\mathrm{C}_{5} \mathrm{H}_{7}^{+}, \mathrm{C}_{6} \mathrm{H}_{5}^{+}$, and $\mathrm{C}_{6} \mathrm{H}_{7}^{+}$are reproduced by the chemistry and composition represented in this model. The processes producing and consuming hydrocarbons larger than the C6 group are discussed in the companion paper (Westlake et al., submitted manuscript, 2011). The implications of this are that the chemistry compiled by Anicich and McEwan [1997] and McEwan and Anicich [2007] have captured the major hydrocarbon production and loss processes. In using the data from Magee et al. [2009] to constrain the ion model we obtain a model that is consistent with the observed neutral spectrum.

[51] For the ions $\mathrm{C}_{3} \mathrm{H}_{5}^{+}, \mathrm{C}_{5} \mathrm{H}_{5}^{+}$, and $\mathrm{C}_{5} \mathrm{H}_{7}^{+}$no measured electron recombination rates exist in the literature. We note that, in general, these ions are overestimated at the high altitudes where recombination is likely to play a role and note that our estimated rate coefficients of $1.5 \times 10^{-6}$ for $\alpha$ and 0.7 for the high temperature $\beta$ and 1.4 for the low temperature $\beta$ may not be the best choice for these ions. Furthermore, the C5 hydrocarbons in particular are chemical end-members with very few ion-molecule loss processes and are therefore more susceptible to electron recombination than the other hydrocarbons that are active participants in the ion-molecule growth processes.

[52] Vuitton et al. [2008] noted that the ion densities below about $1100 \mathrm{~km}$ altitude deviated significantly from the model predictions. At the lowest altitudes the large ions decline in density while the model predictions show a steady increase down to nearly $800 \mathrm{~km}$. These authors attribute this to observational effects manifest in a mistuning of the instrument, as a result of strong atmospheric winds. Figure 14 shows an example of the decline in density versus altitude observed for the T40 flyby (this is similar to the T17 flyby reported by Vuitton et al. [2008]). The region shown in grey is highlighted as the location in which a transmission measurement is taken that can indicate if strong winds have affected the transmission and thereby the derived density. The inset of this figure shows the transmission measurement in which the in-flight selected voltage value for this flyby is slightly off of the center of the curve. The densities shown in Figure 14 are corrected for the decrease in transmission. Furthermore, there is no indication of strong winds. Also plotted is the CAPS-IBS measurement of the total C6 group density (for a description of the procedure see the companion paper (Westlake et al., submitted manuscript, 2011)). Both instruments observe a decline in densities versus altitude, an effect that we find to be physical. This is further supported by the decline in raw fluxes observed by the CAPS-IBS which has a much greater acceptance angle and therefore doesn't suffer from this transmission issues associated with winds or changes in spacecraft charge.

[53] We also mention the issue discussed by Vuitton et al. [2008] in the mass 50 bin. Even with the inclusion of photoionization of $\mathrm{C}_{4} \mathrm{H}_{2}$ Vuitton et al. [2008] found that mass 50 was significantly underestimated in the model. In response to this underestimation Vuitton et al. [2008] increased the production rate of $\mathrm{C}_{4} \mathrm{H}_{2}^{+}$by a factor of 10 . This increased production rate resulted in overestimates at the lowest altitudes of the $\mathrm{C} 4, \mathrm{C} 5$, and $\mathrm{C} 6$ hydrocarbons. The overestimate was attributed not to a deficiency in the model but to instrumental issues. We find that the empirical model shows good correlation with the INMS ion data of the other C4, C5, and C6 hydrocarbons without this increased production process. This indicates that the missing mass 50 density is likely missing $\mathrm{C}_{4} \mathrm{H}_{2}^{+}$produced through some unknown process. Possibilities include the production of $\mathrm{C}_{4} \mathrm{H}_{2}^{+}$through 

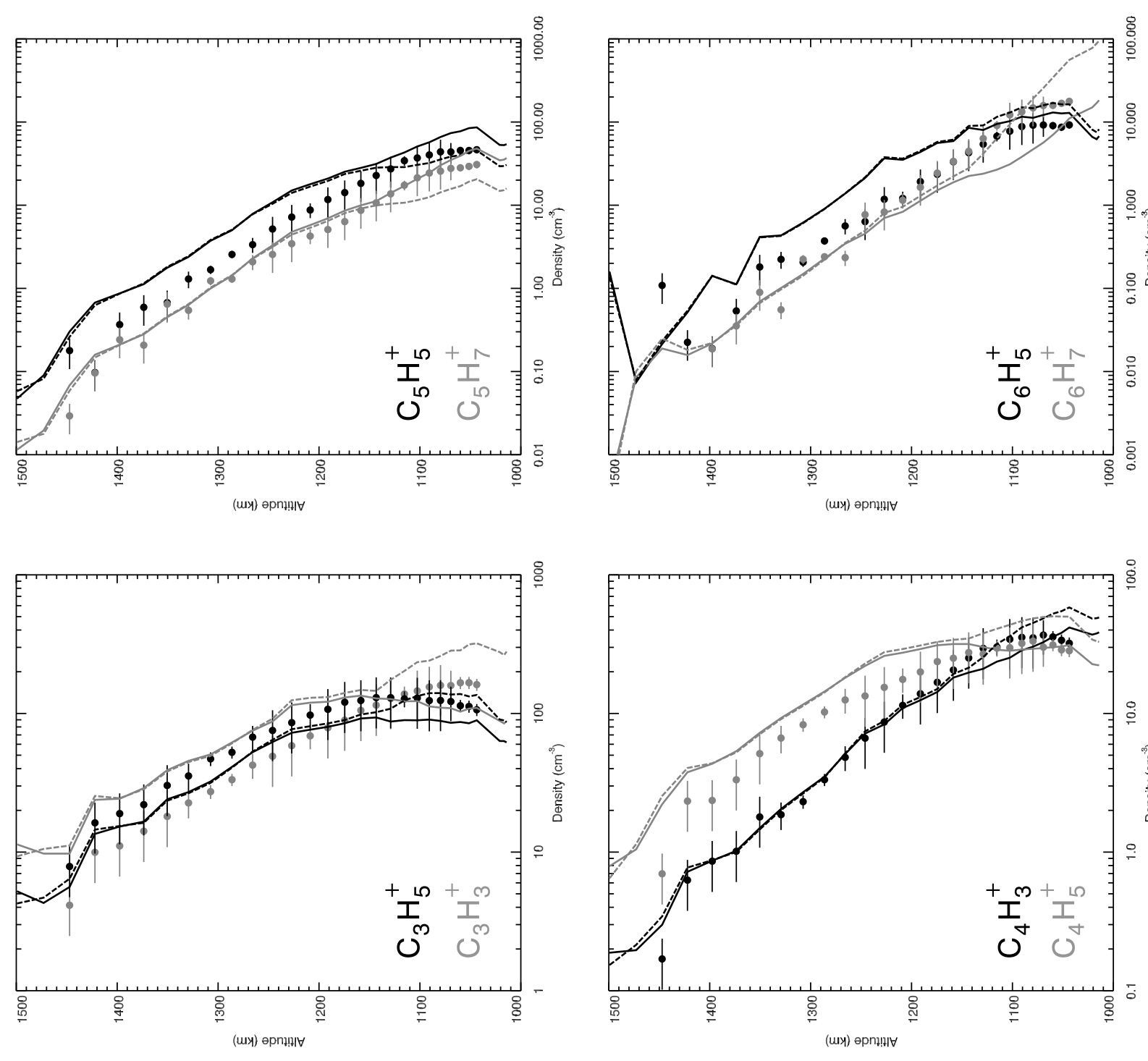

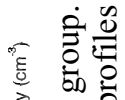
。言も

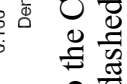




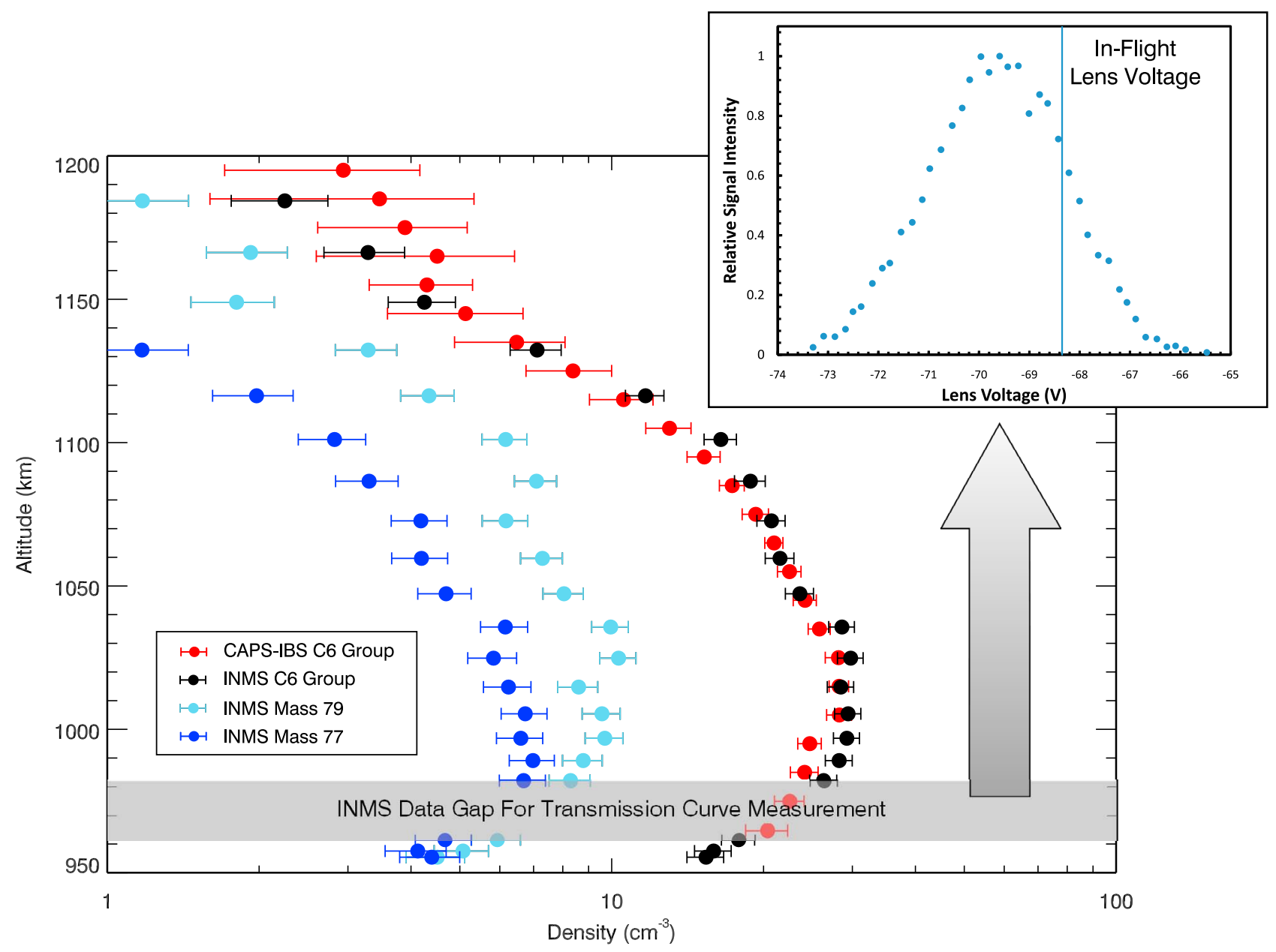

Figure 14. Densities of ions within the C6 group. Shown in red is the CAPS-IBS total C6 group density and in black is the INMS total C6 group density. In light blue is the INMS data from mass 79 which is attributed to $\mathrm{C}_{6} \mathrm{H}_{7}^{+}$and in blue is the mass 77 data which is attributed to $\mathrm{C}_{6} \mathrm{H}_{5}^{+}$.

ion-molecule reactions or $\mathrm{C}_{3} \mathrm{~N}^{+}$which also is not explained in the current chemistry. $\mathrm{C}_{3} \mathrm{~N}$ is expected to be rapidly produced through the photodissociation of $\mathrm{HC}_{3} \mathrm{~N}$ and could be photoionized by photons with wavelengths shorter than about $100 \mathrm{~nm}$ that are available in Titan's upper atmosphere. However, it would not be expected that this process would be more efficient than the photoionization of $\mathrm{C}_{4} \mathrm{H}_{2}$. Therefore, the mass 50 channel remains a mystery.

[54] The derived profiles also point out one of the major issues in producing photochemical models of Titan's ionosphere, namely that one cannot isolate and investigate the chemistry of one ion without, by necessity, including the chemistry of all of the ions that came before it. Therefore errors made in the first and second ions produced after the primary photoionization will propagate through the model and influence the ions produced later. This becomes especially problematic in the calculation of high mass ions, as small errors in the major ion profiles produce large errors in the minor ion profiles. In the accompanying paper we move past this issue by decoupling the chemistry and simply calculating the implied ion density through the production and loss rates. We do, however, note that the coupled chemical model is the only way to approach a self-consistent model of the ionosphere.

\subsection{Nitrogen-Containing Hydrocarbons}

[55] Nitrogen-containing hydrocarbons have been suggested to exist within the INMS spectrum and are evident in the even numbered mass bins [Vuitton et al., 2007]. The ions that have been suggested to occupy a large portion of the spectrum for the most part have not been investigated in the laboratory. Because of this the reactions producing these ions are largely unknown.

[56] Vuitton et al. [2007] used proton exchange reactions with a host of suggested nitrogen-containing hydrocarbons to replicate a single mass spectrum at $1050 \mathrm{~km}$ during the T5 flyby. We intend to use the additional information provided by the altitude structure of the ions to test this hypothesis and identify potential pathways for ionic growth of the nitrogencontaining hydrocarbons.

[57] The lowest mass nitrogen-containing ion observed with significant densities is $\mathrm{NH}_{4}^{+}$which is primarily produced through various proton exchange reactions with neutral ammonia $\left(\mathrm{NH}_{3}\right)$. Yelle et al. [2010] studied the chemical connection between ammonia and $\mathrm{CH}_{2} \mathrm{NH}$ in Titan's atmosphere. Through coupled ion and neutral chemistry it was found that these neutrals are closely linked. From this study densities of $\mathrm{NH}_{3}$ and $\mathrm{CH}_{2} \mathrm{NH}$ were found at $1050 \mathrm{~km}$ to be 

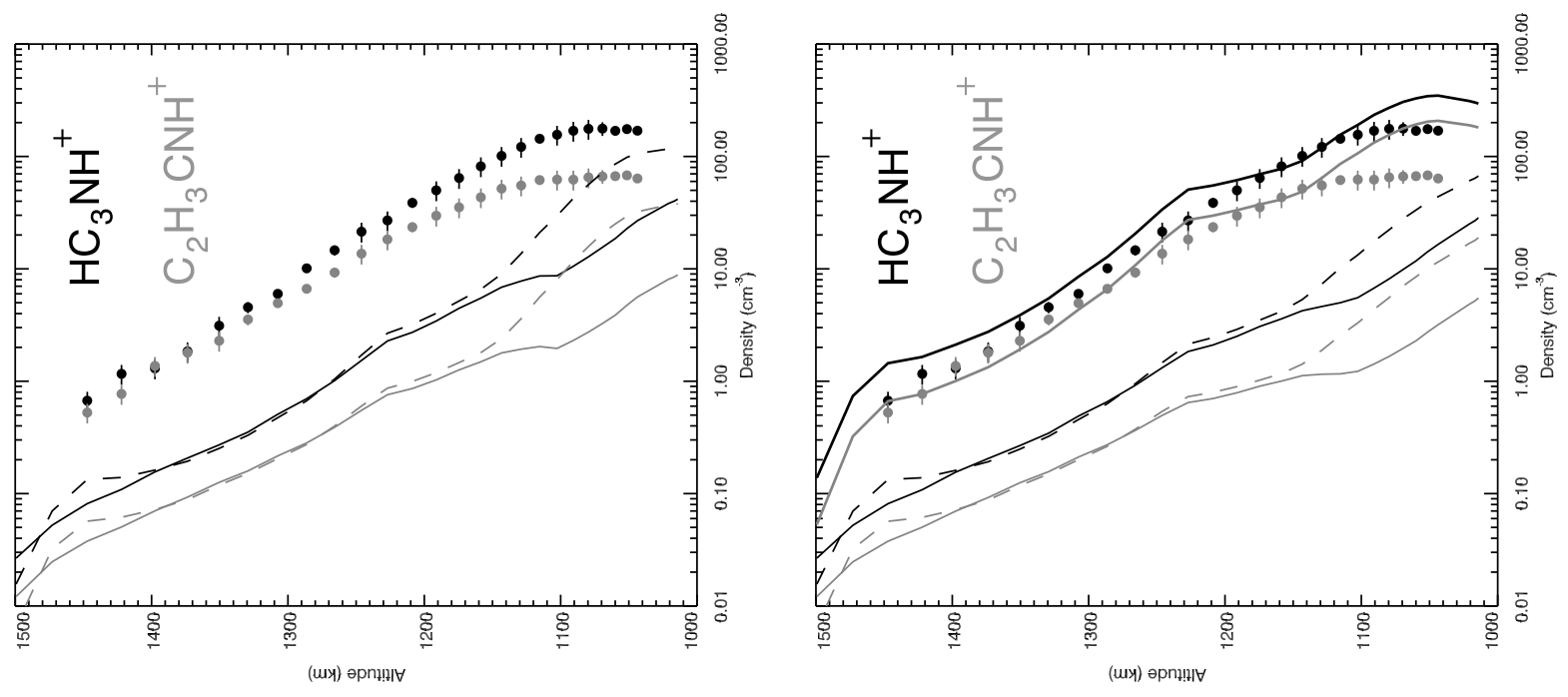

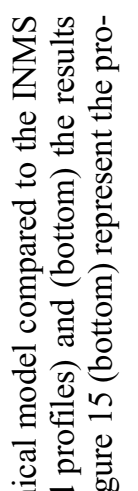
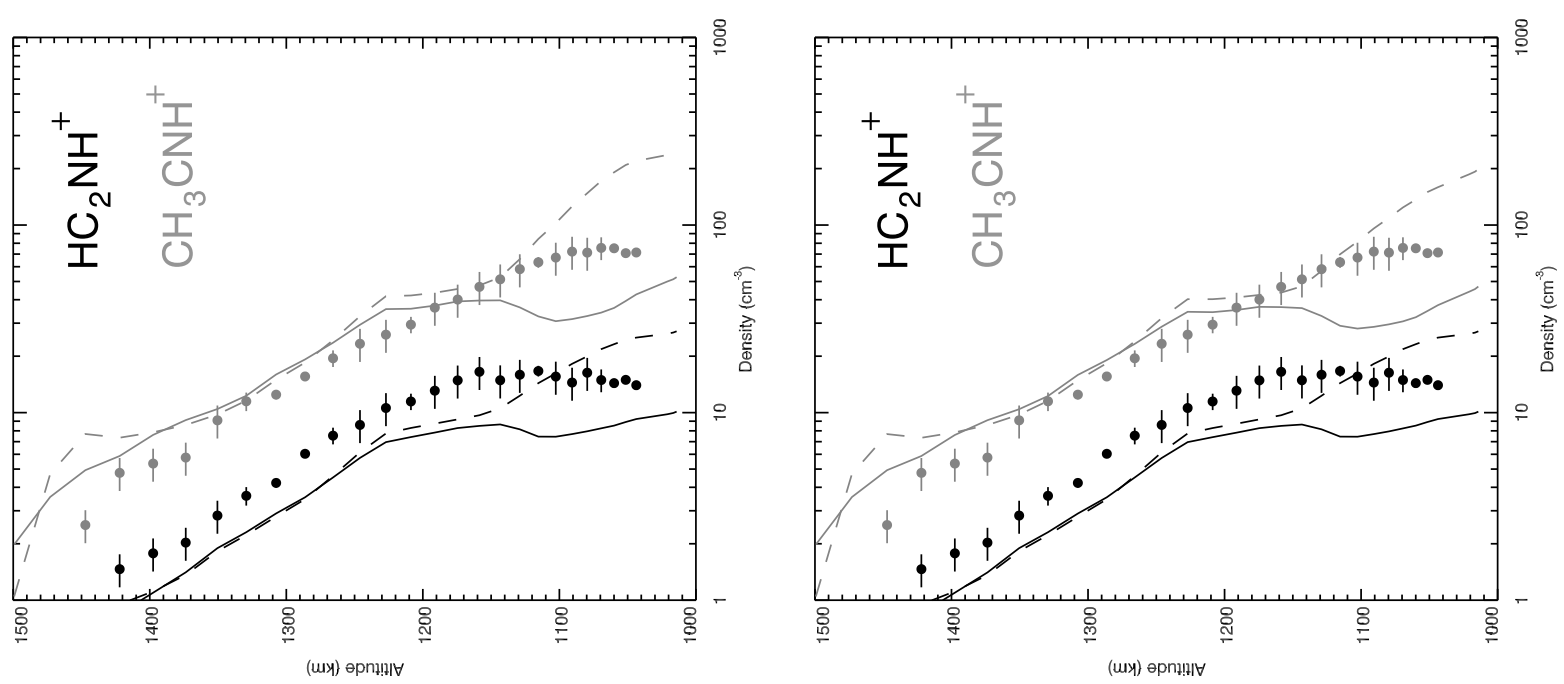

氖寻榁

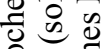

ㄱ.

$\frac{\pi}{2} \frac{\pi}{0}$

온

을

蕰

造运

远

$\frac{\pi}{\partial} \frac{\partial}{0} \frac{\pi}{0}$

i

을 吾

그묘

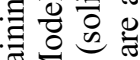

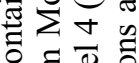

응

$\underbrace{0}_{\infty} \sum^{0}$
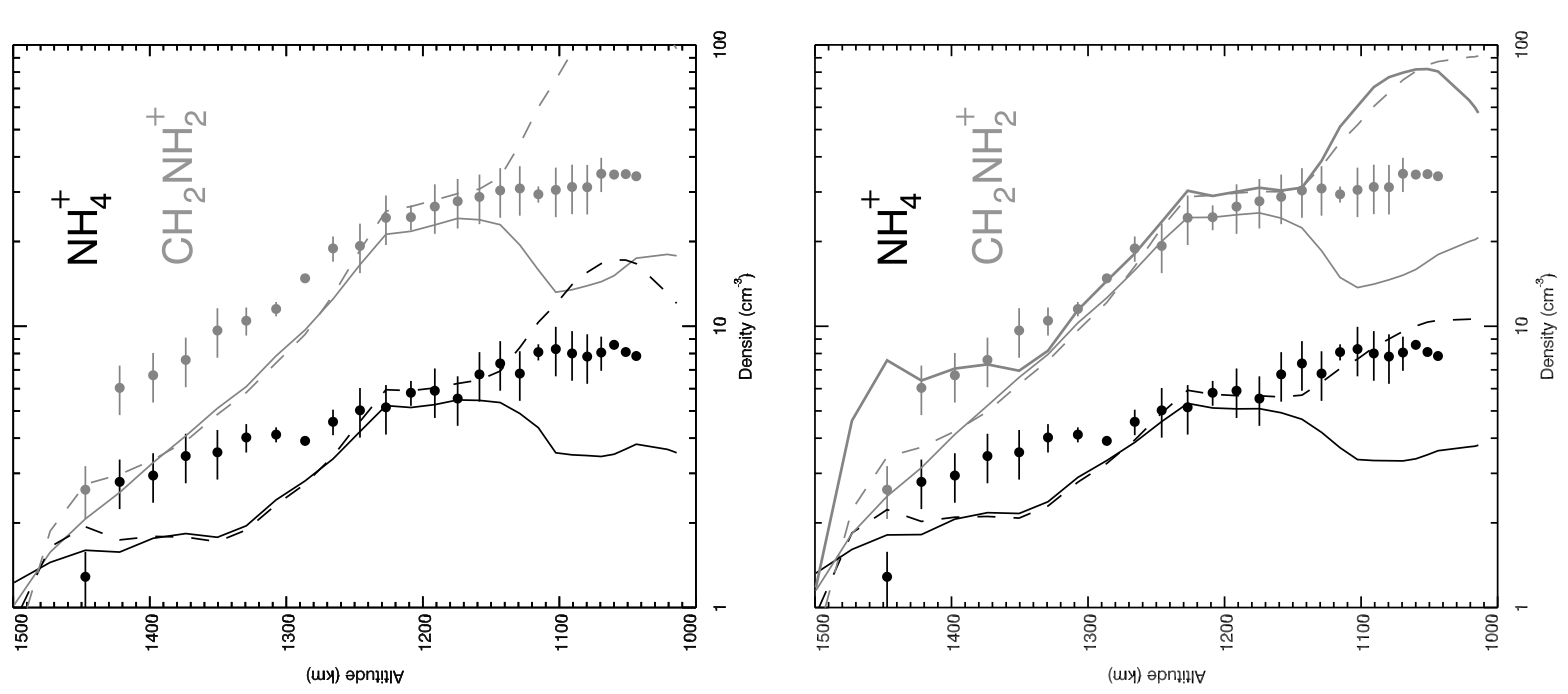

을 畐要

氙

타융

응ㄹㅁㅇ

过

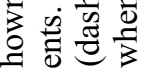

क छ 品

เ

링

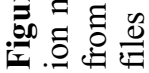



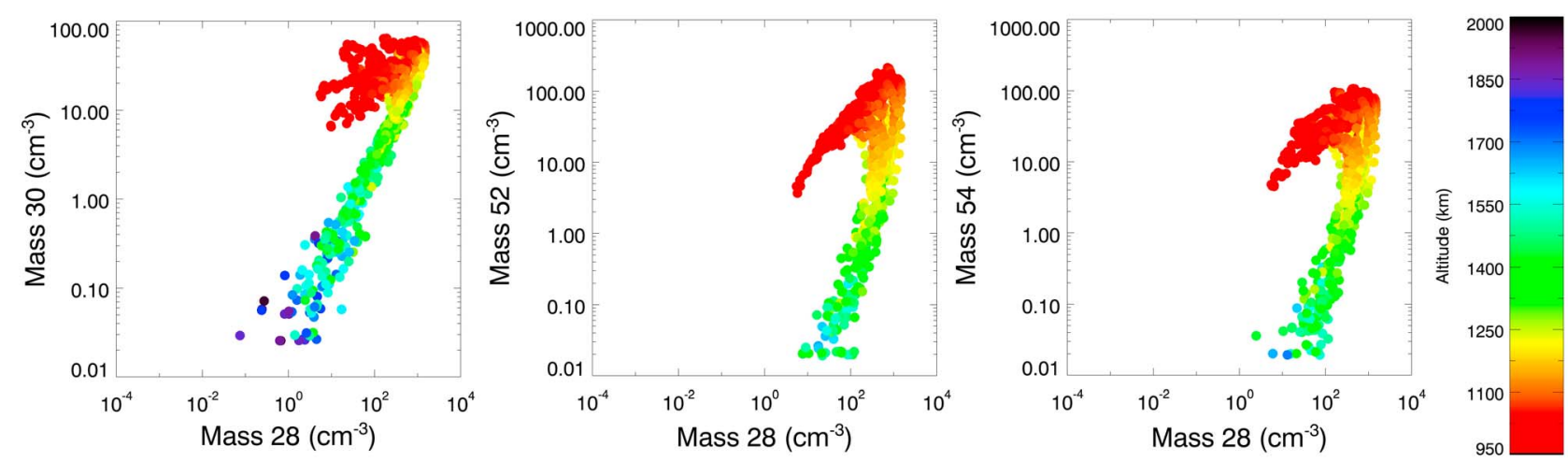

Figure 16. The correlation between the observed densities in mass $28\left(\mathrm{HCNH}^{+}\right)$and mass $30\left(\mathrm{CH}_{2} \mathrm{NH}_{2}^{+}\right)$, mass $52\left(\mathrm{HC}_{3} \mathrm{NH}^{+}\right)$, and mass $54\left(\mathrm{C}_{2} \mathrm{H}_{3} \mathrm{CNH}^{+}\right)$. The colors indicate the altitude of the measurement.

about $5 \times 10^{3} \mathrm{~cm}^{-3}$ and $7 \times 10^{4} \mathrm{~cm}^{-3}$, respectively, corresponding to a mixing ratio of about $5 \times 10^{-7}$ and $7 \times 10^{-6}$ respectively. Interestingly, the calculated altitude profiles of $\mathrm{NH}_{4}^{+}$and $\mathrm{CH}_{2} \mathrm{NH}_{2}^{+}$in that work matched at the lowest altitudes but deviated at higher altitudes indicating either a missing ion production process or some issue with the electron recombination at higher altitudes. In this work we find the best fits to the mass 18 and 30 bins are obtained with mixing ratios ranging from $3 \times 10^{-7}$ to $5 \times 10^{-7}$ for $\mathrm{NH}_{3}$ and $3 \times 10^{-6}$ to $7 \times 10^{-6}$ for $\mathrm{CH}_{2} \mathrm{NH}$ at $1050 \mathrm{~km}$ resulting in the profiles shown in Figure 15. We give a range of values because different values are used in Models 1 and 2 versus Models 3 and 4, with the models including the additional loss of $\mathrm{HCNH}^{+}$requiring larger mixing ratios. We were unable to locate a mass spectrum for $\mathrm{CH}_{2} \mathrm{NH}$ in the literature and are therefore unable to definitively determine if the given mixing ratios are consistent with the neutral spectrum. However, we can give an upper limit as to what could be accommodated by the INMS neutral spectrum. Assuming that at a maximum $100 \%$ of the $\mathrm{CH}_{2} \mathrm{NH}$ would be ionized and appear at mass 30 in the ion spectrum, we find that a mixing ratio of $1 \times 10^{-5}$ can be accommodated, which is consistent with the calculated profiles of Yelle et al. [2010] and the mixing ratios presented here.

[58] We also note here that Smith and Adams [1977] suggested that an associative reaction between $\mathrm{HCNH}^{+}$and $\mathrm{H}_{2}$ may be possible that produces $\mathrm{CH}_{2} \mathrm{NH}_{2}^{+}$. This reaction could possibly be the high altitude sink of $\mathrm{HCNH}^{+}$required for the higher electron temperature models. Furthermore, this reaction may be the high altitude production process missing from the calculations of Yelle et al. [2010]. This reaction has not been investigated in the laboratory at pressures relevant to Titan's ionosphere and we therefore cannot make any conclusions about whether this process actually takes place in Titan's ionosphere. Shown as an alternate profile in Figure 15 is the density of $\mathrm{CH}_{2} \mathrm{NH}_{2}^{+}$calculated using the electron temperatures of Richard et al. [2011] when this assumed reaction takes place with a rate coefficient of $5 \times 10^{-12} \mathrm{~cm}^{3} \mathrm{~s}^{-1}$. Furthermore, the correlation coefficient between the densities observed in mass 28 versus mass 30 is 0.92 indicating that these ions are highly linked. This correlation is shown in Figure 16 (left). It is not possible to differentiate the suggested reaction with $\mathrm{H}_{2}$ and a proton exchange reaction with $\mathrm{CH}_{2} \mathrm{NH}$ in the correlation analysis as they will likely show very similar patterns, however it is clear that these two ions are related through the ionospheric chemistry.

[59] In the grouping from mass 36 to 45 we find that the most prevalent nitrogen-containing ions are $\mathrm{HC}_{2} \mathrm{NH}^{+}$and $\mathrm{CH}_{3} \mathrm{CNH}^{+}$. These ions are well represented by the chemistry of Vuitton et al. [2007] and are plotted in Figure 15. Magee et al. [2009] does not give a mixing ratio for $\mathrm{CH}_{3} \mathrm{CN}$ which is required to produce $\mathrm{CH}_{3} \mathrm{CNH}^{+}$. The mixing ratio of $\mathrm{CH}_{3} \mathrm{CN}$ required to produce the profiles shown in Figure 15 range from $2 \times 10^{-7}$ to $2 \times 10^{-6}$. A reanalysis of the globally averaged spectrum of Magee et al. [2009] shows that a mixing ratio of $2.17 \times 10^{-6}$ can be accommodated, which is within the range of values indicated by the model.

[60] The next group consists primarily of $\mathrm{HC}_{3} \mathrm{NH}^{+}$and $\mathrm{C}_{2} \mathrm{H}_{3} \mathrm{CNH}^{+}$at masses 52 and 54 , respectively. $\mathrm{HC}_{3} \mathrm{NH}^{+}$is primarily thought to be produced through proton exchange with $\mathrm{HC}_{3} \mathrm{~N}$. Given the INMS neutral observation of the globally averaged $\mathrm{HC}_{3} \mathrm{~N}$ mixing ratio at $1050 \mathrm{~km}$ of $(1.48 \pm 0.09) \times 10^{-6}[$ Magee et al., 2009] we find that this process is insufficient to produce all of the observed ion density at mass 52 as can be seen in Figure 15. Vuitton et al. [2007] produced higher $\mathrm{HC}_{3} \mathrm{NH}^{+}$densities using a mixing ratio of $\mathrm{HC}_{3} \mathrm{~N}$ at $1100 \mathrm{~km}$ of $4.0 \times 10^{-5}$ which is substantially greater than that measured by the INMS and cannot be accommodated in the neutral spectrum. Given the current knowledge of the reactions producing $\mathrm{HC}_{3} \mathrm{NH}^{+}$, we cannot show that any reactions are missing in the model of Vuitton et al. [2007]. We also do not expect $\mathrm{C}_{4} \mathrm{H}_{4}^{+}$or $\mathrm{C}_{2} \mathrm{~N}_{2}^{+}$to show significantly greater densities in this mass bin. It is therefore likely that reactions producing $\mathrm{HC}_{3} \mathrm{NH}^{+}$are missing, further supporting the assertion made earlier that a production reaction through $\mathrm{HCNH}^{+}$is needed to accurately replicate the $\mathrm{HC}_{3} \mathrm{NH}^{+}$density.

[61] The density of $\mathrm{C}_{3} \mathrm{H}_{3} \mathrm{~N}$ is also constrained by the INMS neutral spectrum. Using the Magee et al. [2009] value of $(3.46 \pm 0.51) \times 10^{-7}$ we obtain the profile for the protonated $\mathrm{C}_{2} \mathrm{H}_{3} \mathrm{CNH}^{+}$ion shown in Figure 15. Similar to the $\mathrm{HC}_{3} \mathrm{NH}^{+}$profile, we note that Vuitton et al. [2007] utilized much greater mixing ratios, in this case $1 \times 10^{-5}$, to produce the protonated ion. This suggests that reactions that produce this ion are missing. Furthermore, the missing production process must be very efficient or be produced through a major ion as the density underestimation is roughly 70 to 
$90 \mathrm{~cm}^{-3}$. It may be possible that the missing loss reactions for the $\mathrm{HCNH}^{+}$ion occur through acetylene or ethylene producing the $\mathrm{HC}_{3} \mathrm{NH}^{+}$and $\mathrm{C}_{2} \mathrm{H}_{3} \mathrm{CNH}^{+}$ions. Processes in the termolecular pressure regime between $\mathrm{HCNH}^{+}$and acetylene and ethylene have been identified that produce $\mathrm{C}_{3} \mathrm{H}_{4} \mathrm{~N}^{+}$and $\mathrm{C}_{3} \mathrm{H}_{6} \mathrm{~N}^{+}$[Milligan et al., 2001]. We note that studies have also shown that these are not the protonated versions of the ions but are more likely to be four membered cyclic-like structures. This is because there exists a significant barrier between the initial reaction and the production of the protonated version of the ions [Milligan et al., 2001].

[62] Shown as alternative profiles in Figure 15 are profiles calculated when a reaction between $\mathrm{HCNH}^{+}$and a $\mathrm{C} 2$ hydrocarbon produces $\mathrm{HC}_{3} \mathrm{NH}^{+}$or $\mathrm{C}_{2} \mathrm{H}_{3} \mathrm{CNH}^{+}$with a rate coefficient of $5 \times 10^{-11} \mathrm{~cm}^{3} \mathrm{~s}^{-1}$. We find that it is possible to reproduce the altitude profiles of these ions using this process. Shown in Figure 16 are the correlations between mass 28 and masses 52 and 54 as observed by the INMS. The correlation coefficients are 0.66 and 0.70 , respectively, for mass 52 and mass 54 . The correlation coefficient is reduced as the curve in the profile effects the calculation of the Pearson correlation coefficient. These ions are clearly related although their linear correlation is relatively low. This does not absolutely determine whether this reaction takes place in Titan's ionosphere, but it does suggest that these ions are related through the ionospheric chemistry.

[63] The nitrogen-containing hydrocarbons past the fourth mass grouping are for the most part unknown. Vuitton et al. [2007] suggested several ions exist with a single nitrogen in the spectrum. We note, however, that all of these ions are produced through the proton exchange of a major ion with a neutral that we do not currently know how to produce photochemically. We maintain this chemistry in the model as it does produce good fits to the altitude profiles, however we cannot definitively discuss the chemistry of these ions without further measurements of the reactions of these ions. Furthermore, it is likely that some of these ions have two or more nitrogens incorporated as has been indicated by the laboratory simulations of Titan's tholins [see, e.g., Carrasco et al., 2009].

\section{Conclusions}

[64] We have introduced two new techniques for analyzing Titan's ionospheric data from the INMS. We have calculated the mass-to-mass correlation within the INMS ion spectrum. This correlation displays links between ion species and groups. These links hold the clues to any missing chemical processes and could be useful to motivate specific laboratory studies. We have also presented the empirical model that uses the INMS data as the basis for calculating specific ion densities. This tool is useful for probing single reactions and for determining which processes are most important. We utilized this tool to determine the processes responsible for the production and loss of $\mathrm{HCNH}^{+}$as well as to probe potential loss processes.

[65] In studying Titan's ionosphere using the data retrieved from the INMS instrument and a 1-D photochemical model, several observations were apparent. We find that the densities of the primary ions produced from the ionization of $\mathrm{CH}_{4}$ and $\mathrm{N}_{2}$ are well described by a 1-D photochemical model. The primary production processes and the ion-molecule chemistry mainly control these ions. We find that past these initial ions several processes, many that are uncertain, are responsible for the observed ion densities.

[66] In this work we focused on how the electron temperatures influenced the density profiles of the major ions $\mathrm{CH}_{5}^{+}, \mathrm{C}_{2} \mathrm{H}_{5}^{+}$, and $\mathrm{HCNH}^{+}$. We found that electron temperatures that converge to the neutral temperature at the lowest altitudes better represent these ions. Further improvements of these profiles could be achieved through investigating the chemistry of $\mathrm{HCNH}^{+}$and further investigation of the electron temperature profiles. We found that the $\mathrm{HCNH}^{+}$density could be reproduced by introducing first order ion-molecule reactions with $\mathrm{H}_{2}, \mathrm{C}_{2} \mathrm{H}_{2}$, and $\mathrm{C}_{2} \mathrm{H}_{4}$. We also found that these processes may be responsible for the production of the ions $\mathrm{CH}_{2} \mathrm{NH}_{2}^{+}, \mathrm{C}_{3} \mathrm{H}_{4} \mathrm{~N}^{+}$, and $\mathrm{C}_{3} \mathrm{H}_{6} \mathrm{~N}^{+}$.

[67] The major hydrocarbon densities are reproduced by the chemistry of Anicich and McEwan [1997] with the additions of McEwan and Anicich [2007] and Vuitton et al. [2007]. These ions are produced primarily through ionmolecule addition reactions with the abundant minor hydrocarbons acetylene and ethylene. Further investigations of the recombination rates of the $\mathrm{C} 5$ hydrocarbons are needed to improve the calculated spectra.

[68] The nitrogen-containing hydrocarbons are much more uncertain than their pure hydrocarbon counterparts. We find that the proton exchange theory presented by Vuitton et al. [2007] can reproduce spectra at single altitudes given a sufficient density of the minor neutral. However, these densities should be observed in the neutral spectrum and in some cases have been calculated by Magee et al. [2009]. The INMS observations constrain the amount of these neutrals to be expected. In using these constraints we find that several ions are not well represented by the model. It is likely that the underestimation of these densities results from a lack of sufficient knowledge of the chemistry of these ions. We find that there is a high correlation between $\mathrm{HCNH}^{+}$and these ions indicating that some of the missing chemistry may be related to association reactions between $\mathrm{HCN}$ or $\mathrm{HCNH}^{+}$and various other species.

[69] Acknowledgments. We thank Pascal Pernot for several discussions relating to this work. This work was supported by NASA Headquarters under the NASA Earth and Space Science Fellowship Program (grant "NNX08AW24H"). NC thanks the ANR-09-JCJC-0038 contract for its financial support.

\section{References}

Ågren, K., J. Wahlund, P. Garnier, R. Modolo, J. Cui, M. Galand, and I. Müller-Wodarg (2009), On the ionospheric structure of Titan, Planet. Space Sci., 57(14-15), 1821-1827.

Anicich, V., and M. McEwan (1997), Ion-molecule chemistry in Titan's ionosphere, Planet. Space Sci., 45(8), 897-921.

Banaszkiewicz, M., L. Lara, R. Rodrigo, J. Lopez-Moreno, and G. MolinaCuberos (2000), A coupled model of Titan's atmosphere and ionosphere, Icarus, 147(2), 386-404.

Bell, J. M., et al. (2010a), Simulating the one-dimensional structure of Titan's upper atmosphere: 1. Formulation of the Titan Global Ionosphere-Thermosphere Model and benchmark simulations, J. Geophys. Res., 115, E12002, doi:10.1029/2010JE003636.

Bell, J. M., et al. (2010b), Simulating the one-dimensional structure of Titan's upper atmosphere: 2. Alternative scenarios for methane escape, J. Geophys. Res., 115, E12018, doi:10.1029/2010JE003638.

Bell, J. M., et al. (2011), Simulating the one-dimensional structure of Titan's upper atmosphere: 3. Mechanisms determining methane escape, J. Geophys. Res., 116, E11002, doi:10.1029/2010JE003639. 
Carrasco, N., and P. Pernot (2007), Modeling of branching ratio uncertainty in chemical networks by dirichlet distributions, J. Phys. Chem. A, 111(18), 3507-3512.

Carrasco, N., E. Hébrard, M. Banaszkiewicz, M. Dobrijevic, and P. Pernot (2007), Influence of neutral transport on ion chemistry uncertainties in Titan ionosphere, Icarus, 192(2), 519-526.

Carrasco, N., C. Alcaraz, O. Dutuit, S. Plessis, R. Thissen, V. Vuitton, R. Yelle, and P. Pernot (2008a), Sensitivity of a Titan ionospheric model to the ion-molecule reaction parameters, Planet. Space Sci., 56(12), 1644-1657.

Carrasco, N., S. Plessis, M. Dobrijevic, and P. Pernot (2008b), Toward a reduction of the bimolecular reaction model for Titan's ionosphere, Int. J. Chem. Kinet., 40(11), 699-709.

Carrasco, N., et al. (2009), Chemical characterization of Titan's tholins: Solubility, morphology and molecular structure revisited, J. Phys. Chem. A, 113(42), 11,195-11,203.

Coates, A., F. Crary, G. Lewis, D. Young, J. Waite Jr., and E. Sittler Jr. (2007), Discovery of heavy negative ions in Titan's ionosphere, Geophys Res. Lett., 34, L22103, doi:10.1029/2007GL030978.

Crary, F., B. Magee, K. Mandt, J. Waite Jr., J. Westlake, and D. Young (2009), Heavy ions, temperatures and winds in Titan's ionosphere Combined Cassini CAPS and INMS observations, Planet. Space Sci., 57(14-15), 1847-1856.

Cravens, T., et al. (2005), Titan's ionosphere: Model comparisons with Cassini Ta data, Geophys. Res. Lett., 32, L12108, doi:10.1029/ 2005GL023249.

Cravens, T., et al. (2006), Composition of Titan's ionosphere, Geophys. Res. Lett., 33, L07105, doi:10.1029/2005GL025575.

Cravens, T., et al. (2009), Model-data comparisons for Titan's nightside ionosphere, Icarus, 199(1), 174-188.

Cravens, T., R. Yelle, J. Wahlund, D. Shemansky, and A. Nagy (2010), Composition and structure of the ionosphere and thermosphere, in Titan From Cassini-Huygens, edited by R. H. Brown, J.-P. Lebreton, and J. H. Waite, pp. 259-295, Springer, Dordrecht, Netherlands.

Cui, J., et al. (2009), Analysis of Titan's neutral upper atmosphere from Cassini Ion Neutral Mass Spectrometer measurements, Icarus, 200(2), 581-615.

De La Haye, V., J. Waite Jr., T. Cravens, I. Robertson, and S. Lebonnois (2008), Coupled ion and neutral rotating model of Titan's upper atmosphere, Icarus, 197(1), 110-136.

Edwards, S., C. Freeman, and M. McEwan (2008), The ion chemistry of methylenimine and propionitrile and their relevance to Titan, Int. J. Mass Spectrom., 272(1), 86-90.

Fox, J., and R. Yelle (1997), Hydrocarbon ions in the ionosphere of Titan Geophys. Res. Lett., 24(17), 2179-2182.

Galand, M., R. Yelle, J. Cui, J. Wahlund, V. Vuitton, A. Wellbrock, and A. Coates (2010), Ionization sources in Titan's deep ionosphere, J. Geophys. Res., 115, A07312, doi:10.1029/2009JA015100.

Herbst, E. (1976), Radiative association in dense, H2-containing interstellar clouds, Astrophys. J., 205, 94-102, doi:10.1086/154253.

Herbst, E., D. Smith, N. Adams, and B. McIntosh (1989), Association reactions. Theoretical shortcomings, J. Chem. Soc., Faraday Trans. 2, 85(10), 1655-1664

Keller, C., T. Cravens, and L. Gan (1992), A model of the ionosphere of Titan, J. Geophys. Res., 97(A8), 12,117-12,135.

Keller, C., V. Anicich, and T. Cravens (1998), Model of Titans ionosphere with detailed hydrocarbon ion chemistry, Planet. Space Sci., 46(9-10), 1157-1174.

Krasnopolsky, V. (2009), A photochemical model of Titan's atmosphere and ionosphere, Icarus, 201(1), 226-256.

Lavvas, P., M. Galand, R. Yelle, A. Heays, B. Lewis, G. Lewis, and A. Coates (2011), Energy deposition and primary chemical products in Titan's upper atmosphere, Icarus, 213, 233-251.

Ma, Y., A. Nagy, T. Cravens, I. Sokolov, K. Hansen, J. Wahlund, F. Crary, A. Coates, and M. Dougherty (2006), Comparisons between mhd mode calculations and observations of Cassini flybys of Titan, J. Geophys. Res., 111, A05207, doi:10.1029/2005JA011481.

Magee, B., J. Waite, K. Mandt, J. Westlake, J. Bell, and D. Gell (2009), INMS-derived composition of Titan's upper atmosphere: Analysis methods and model comparison, Planet. Space Sci., 57(14-15), 1895-1916.

McEwan, M., and V. Anicich (2007), Titan's ion chemistry: A laboratory perspective, Mass Spectrom. Rev., 26(2), 281-319.

McLain, J., and N. Adams (2009), Flowing afterglow studies of temperature dependencies for electron dissociative recombination of $\mathrm{HCNH}^{+}$ $\mathrm{CH}_{3} \mathrm{CNH}^{+}$and $\mathrm{CH}_{3} \mathrm{CH}_{2} \mathrm{CNH}^{+}$and their symmetrical proton-bound dimers, Planet. Space Sci., 57(13), 1642-1647.

McLain, J., V. Poterya, D. Christopher, L. Babcock, and N. Adams (2004) Flowing afterglow studies of the temperature dependencies for dissociative recombination of $\mathrm{O}_{2}^{+}, \mathrm{CH}_{5}^{+}, \mathrm{C}_{2} \mathrm{H}_{5}^{+}$, and $\mathrm{C}_{6} \mathrm{H}_{7}^{+}$with electrons, J. Phys. Chem. A, 108(32), 6704-6708.

Milligan, D., C. Freeman, R. Maclagan, M. McEwan, P. Wilson, and V. Anicich (2001), Termolecular ion-molecule reactions in Titan's atmosphere. Part II: The structure of the association adducts of $\mathrm{HCNH}^{+}$with $\mathrm{C}_{2} \mathrm{H}_{2}$ and $\mathrm{C}_{2} \mathrm{H}_{4}$, J. Am. Soc. Mass Spectrom., 12(5), 557-564.

Richard, M. S., T. E Cravens, I. P. Robertson, J. H. Waite, J-E. Wahlund, F. J. Crary, and A. J. Coates (2011), Energetics of Titan's ionosphere: Model comparisons with Cassini data, J. Geophys. Res., 116, A09310, doi:10.1029/2011JA016603.

Richards, P., J. Fennelly, and D. Torr (1994), Euvac: A solar euv flux model for aeronomic calculations, J. Geophys. Res., 99(A5), 8981-8992.

Ridley, A., Y. Deng, and G. Tóth (2006), The global ionospherethermosphere model, J. Atmos. Sol.-Terr. Phys., 68(8), 839-864.

Robertson, I., et al. (2009), Structure of Titan's ionosphere: Model comparisons with Cassini data, Planet. Space Sci., 57(14-15), 1834-1846.

Rymer, A., H. Smith, A. Wellbrock, A. Coates, and D. Young (2009), Discrete classification and electron energy spectra of Titan's varied magnetospheric environment, Geophys. Res. Lett., 36, L15109, doi:10.1029/ 2009GL039427.

Semaniak, J., et al. (2001), Dissociative recombination of $\mathrm{HCNH}^{+}$: Absolute cross-sections and branching ratios, Astrophys. J. Suppl. Ser., 135, 275-283.

Smith, D., and N. Adams (1977), Molecular synthesis in interstellar clouds-Some relevant laboratory measurements, Astrophys. J., 217, 741-748.

Tobiska, W., and C. Barth (1990), A solar euv flux model, J. Geophys. Res., 95, 8243-8251.

Torr, M., D. Torr, and R. Ong (1980), Comparison of the $\mathrm{N}_{2}^{+}$photochemistry at different phases of the solar cycle, J. Geophys. Res., 85(A5), 2171-2176

Vigren, E., M. Hamberg, V. Zhaunerchyk, M. Kamińska, R. Thomas, M. Larsson, T. Millar, C. Walsh, and W. Geppert (2009), The dissociative recombination of protonated acrylonitrile, $\mathrm{CH} 2 \mathrm{CHCNH}+$, with implications for the nitrile chemistry in dark molecular clouds and the upper atmosphere of Titan, Astrophys. J., 695, 317-324.

Vuitton, V., R. Yelle, and V. Anicich (2006), The nitrogen chemistry of Titan's upper atmosphere revealed, Astrophys. J., 647, L175-L178.

Vuitton, V., R. Yelle, and M. McEwan (2007), Ion chemistry and Ncontaining molecules in Titan's upper atmosphere, Icarus, 191(2), $722-742$

Vuitton, V., R. Yelle, and J. Cui (2008), Formation and distribution of benzene on Titan, J. Geophys. Res., 113, E05007, doi:10.1029/ 2007JE002997.

Vuitton, V., P. Lavvas, R. Yelle, M. Galand, A. Wellbrock, G. Lewis, A. Coates, and J. Wahlund (2009a), Negative ion chemistry in Titan's upper atmosphere, Planet. Space Sci., 57(13), 1558-1572.

Vuitton, V., R. Yelle, and P. Lavvas (2009b), Composition and chemistry of Titan's thermosphere and ionosphere, Philos. Trans. R. Soc. A, 367 (1889), 729-741.

Wahlund, J., et al. (2009), On the amount of heavy molecular ions in Titan's ionosphere, Planet. Space Sci., 57(14-15), 1857-1865.

Waite, J., D. Young, T. Cravens, A. Coates, F. Crary, B. Magee, and J. Westlake (2007), The process of tholin formation in Titan's upper atmosphere, Science, 316(5826), 870-875.

Westlake, J., J. Bell, J. Waite Jr., R. Johnson, J. Luhmann, K. Mandt, B. Magee, and A. Rymer (2011), Titan's thermospheric response to various plasma environments, J. Geophys. Res., 116, A03318, doi:10.1029/ 2010JA016251.

Wilson, E., and S. Atreya (2004), Current state of modeling the photochemistry of Titan's mutually dependent atmosphere and ionosphere, J. Geophys. Res., 109, E06002, doi:10.1029/2003JE002181.

Wilson, P. C. Freeman, and M. McEwan (1993), Isomers of $\mathrm{C}_{3} \mathrm{H}_{6} \mathrm{~N}^{+}$and the interstellar synthesis of $\mathrm{C}_{2} \mathrm{H}_{5} \mathrm{CN}$, Int. J. Mass Spectrom. Ion Processes, 128(1-2), 83-89.

Yelle, R., V. Vuitton, P. Lavvas, S. Klippenstein, M. Smith, S. Hörst, and J. Cui (2010), Formation of $\mathrm{NH}_{3}$ and $\mathrm{CH}_{2} \mathrm{NH}$ in Titan's upper atmosphere, Faraday Discuss., 147, 1-19.

Yung, Y., M. Allen, and J. Pinto (1984), Photochemistry of the atmosphere of Titan-Comparison between model and observations, Astrophys. J. Suppl. Ser., 55(3), 465-506.

Zabka, J., M. Polasek, D. Ascenzi, P. Tosi, J. Roithova, and D. Schroder (2009), Reactivity of $\mathrm{C}_{2} \mathrm{H}_{5}^{+}$with benzene: Formation of ethylbenzenium ions and implications for Titan's ionospheric chemistry, J. Phys. Chem. A, 113(42), 11,153-11,160.

J. M. Bell, B. A. Magee, K. E. Mandt, and J. H. Waite Jr., Space Science and Engineering Division, Southwest Research Institute, 6220 
Culebra Rd., San Antonio, TX 78228, USA. (jbell@swri.edu; bmagee@swri. edu; kmandt@swri.edu; hwaite@swri.edu)

N. Carrasco, Laboratoire Atmosphres, Milieux, Observations Spatiales, Université de Versailles Saint-Quentin-en-Yvelines, 11 Blvd. d'Alembert, F-78280 Guyancourt, France.
J.-E. Wahlund, Swedish Institute of Space Physics, Box 537, SE-751 21 Uppsala, Sweden.

J. H. Westlake, Applied Physics Laboratory, Johns Hopkins University, 11101 Johns Hopkins Rd., Laurel, MD 20723-6005, USA. (joseph.westlake@ jhuapl.edu) 